\title{
GEOTRACES inter-calibration of the stable silicon isotope composition of dissolved silicic acid in seawater
}

\author{
Grasse Patricia ${ }^{1,2}$, Brzezinski Mark A. ${ }^{2,}{ }^{*}$, Cardinal Damien ${ }^{3}$, De Souza Gregory F. ${ }^{4}$, Andersson Per ${ }^{3}$, \\ Closset Ivia ${ }^{3}$, Cao Zhimian ${ }^{6}$, Dai Minhan ${ }^{6}$, Ehlert Claudia ${ }^{7}$, Estrade Nicolas ${ }^{8,15}$, Francois Roger ${ }^{8}$, \\ Frank Martin, Jiang Guibin ${ }^{9}$, Jones Janice L. ${ }^{2}$, Kooijman Ellen ${ }^{5}$, Liu Qian ${ }^{9}$, Lu Dawei ${ }^{9}$, \\ Pahnke Katharina ${ }^{7}$, Ponzevera Emmanuel ${ }^{10}$, Schmitt Melanie ${ }^{5}$, Sun Xiaole ${ }^{11,}, 16$, Sutton Jill ${ }^{12}$, \\ Thil Francois $^{13}$, Weis Dominique ${ }^{8}$, Wetzel Florian ${ }^{4}$, Zhang Anyu ${ }^{14}$, Zhang Jing ${ }^{14}$, Zhang Zhouling ${ }^{6}$
}

${ }^{1}$ GEOMAR, Helmholtz Ctr Ocean Res Kiel, Ocean Circulat \& Climate Dynam, Wischhofstr 1-3, D-24148 Kiel, Germany.

${ }^{2}$ Univ Calif Santa Barbara, Inst Marine Sci, Dept Ecol Evolut \& Marine Biol, Santa Barbara, CA 93106 USA.

${ }^{3}$ Univ Paris 06, Sorbonne Univ UPMC, CNRS IRD MNHN, LOCEAN Lab, 4 PI Jussieu, F-75005 Paris, France.

${ }_{5}^{4}$ Swiss Fed Inst Technol, Inst Geochemistry \& Petr, Clausiusstrasse 25, CH-8092 Zurich, Switzerland.

${ }^{5}$ Swedish Museum Nat Hist, Dept Geosci, S-10405 Stockholm, Sweden.

${ }_{7}^{6}$ Xiamen Univ, State Key Lab Marine Environm Sci, Xiamen, Peoples R China.

${ }^{7}$ Carl von Ossietzky Univ Oldenburg, Inst Chem \& Biol Marine Environm ICBM, Max Planck Res Grp

Marine Isotope Geochem, Carl Von Ossietzky Str 9-11, D-26129 Oldenburg, Germany.

${ }^{8}$ Univ British Columbia, Pacific Ctr Isotop \& Geochem Res, Dept Earth Ocean \& Atmospher Sci,

Vancouver, BC V6T IZ4, Canada.

${ }_{9}^{9}$ Chinese Acad Sci, Res Ctr Eco Environm Sci, State Key Lab Environm Chem Ecotoxicol, 18

Shuangqing Rd, Beijing 100085, Peoples R China.

${ }_{10}$ Unit Rech Geosci Marines, IFREMER, F-29870 Plouzane, France.

${ }_{11}^{11}$ Stockholm Univ, Dept Environm Sci \& Analyt Chem, Stockholm, Sweden.

${ }^{12}$ Univ Brest, CNRS, IRD, IFREMER,LEMARIUEM, Rue Dumont Urville, Plouzane, France.

${ }^{13}$ LSCE IPSL, Lab CEA CNRS UVSQ, Lab Sci Climat \& Environm, Domaine CNRS, Bat 12,Ave

Terrasse, F-91198 Gif Sur Yvette, France.

${ }_{14}^{14}$ China Normal Univ, State Key Lab Estuarine \& Coastal Res, Shanghai 200062, Peoples R China.

${ }^{15}$ LEGOS, Equipe TIM, Observ Midi Pyrenes, 14 Edouard Belin, F-31400 Toulouse, France.

${ }^{16}$ Stockholm Univ, Balt Sea Ctr, S-10691 Stockholm, Sweden.

* Corresponding author : Mark A. Brzezinski, email address : mark.brzezinski@lifesci.ucsb.edu

\begin{abstract}
:
The first inter-calibration study of the stable silicon isotope composition of dissolved silicic acid in seawater, delta Si-30(OH)(4), is presented as a contribution to the international GEOTRACES program. Eleven laboratories from seven countries analyzed two seawater samples from the North Pacific subtropical gyre (Station ALOHA) collected at $300 \mathrm{~m}$ and at $1000 \mathrm{~m}$ water depth. Sampling depths were
\end{abstract}


chosen to obtain samples with a relatively low $(9 \mathrm{mmol} \mathrm{L}-1,300 \mathrm{~m})$ and a relatively high $(113 \mathrm{mmol} \mathrm{L}-1$, $1000 \mathrm{~m}$ ) silicic acid concentration as sample preparation differs for low- and highconcentration samples. Data for the $1000 \mathrm{~m}$ water sample were not normally distributed so the median is used to represent the central tendency for the two samples. Median delta Si-30(OH)(4) values of +1.66 \& for the lowconcentration sample and $+1.25 \&$ for the high-concentration sample were obtained. Agreement among laboratories is overall considered very good; however, small but statistically significant differences among the mean isotope values obtained by different laboratories were detected, likely reflecting interlaboratory differences in chemical preparation including pre-concentration and purification methods together with different volumes of seawater analyzed, and the use of different mass spectrometers including the Neptune MC-ICP-MS (Thermo Fisher (TM), Germany), the Nu Plasma MC-ICP-MS (Nu Instruments (TM), Wrexham, UK), and the Finnigan (TM) (now Thermo Fisher (TM), Germany) MAT 252 IRMS. Future studies analyzing delta Si-30(OH)(4) in seawater should also analyze and report values for these same two reference waters in order to facilitate comparison of data generated among and within laboratories over time. 


\section{Introduction}

The stable isotope composition of silicon in dissolved silicic acid in seawater, $\delta^{30} \mathrm{Si}(\mathrm{OH})_{4}$, is a powerful tool for understanding the silicon cycle in the ocean as it reflects changes in the biological utilization of silicic acid, $\mathrm{Si}(\mathrm{OH})_{4}$, by diatoms in surface water as well as water mass mixing. $\delta^{30} \mathrm{Si}$ measurements in both $\mathrm{Si}(\mathrm{OH})_{4}$ and in biogenic silica are essential to fully understand the marine Si cycle, in particular to characterize Si sources and sinks in order to better constrain the Si budget in the ocean (Tréguer and De La Rocha, 2013). Besides their importance in understanding the present day Si cycle, $\delta^{30} \mathrm{Si}$ measurements are increasingly being used to assess past changes through the isotopic analysis of $\mathrm{Si}$ in biogenic silica within diatom frustules and within sponge spicules from marine sediments (e.g. Reynolds et al., 2008; Maier et al., 2013; Ehlert et al., 2015).

Beginning with the first report of $\delta^{30} \mathrm{Si}$ measurements in natural waters by De La Rocha et al. (2000), there has been a growing number of publications, especially in the past five years, reporting $\delta^{30} \mathrm{Si}(\mathrm{OH})_{4}$ values from marine systems, covering locations in the Southern, Atlantic, Pacific, and Indian Oceans as well as large estuaries (e.g. Cardinal et al., 2005; Reynolds et al., 2006; Cao et al., 2012; de Souza et al, 2012a; Brzezinski \& Jones, 2015; Singh et al., 2015, Zhang et al. 2015a). This data set is anticipated to grow as part of the international GEOTRACES program that seeks to understand the global-scale distributions of trace elements and their isotopes in the marine environment (http://www.geotraces.org). All Si isotope data obtained by the GEOTRACES and other programs need to be fully comparable in order to better understand $\mathrm{Si}$ isotope systematics across the global ocean, and to validate models of the global marine $\delta^{30} \mathrm{Si}(\mathrm{OH})_{4}$ distribution (de Souza et al., 2014, 2015; Holzer and Brzezinski, 2015; Gao et al., 2016). However, such efforts are challenged by the lack of seawater reference material of known $\delta^{30} \mathrm{Si}(\mathrm{OH})_{4}$ to intercalibrate data generated by different laboratories or within a laboratory through time, as is currently only possible for solid siliceous materials (Reynolds et al., 2007).

The procedures and instrumentation used in stable $\mathrm{Si}$ isotope analysis have evolved substantially over the last two decades. The first precise $\delta^{30}$ Si measurements of marine dissolved and particulate Si were conducted using a VG Prism gas source isotope ratio mass spectrometer (IRMS) with samples prepared using a manual fluorination line that employed $\mathrm{F}_{2}$ gas to convert $\mathrm{Si}$ recovered from either seawater or from biogenic silica as solid $\mathrm{SiO}_{2}$ to $\mathrm{SiF}_{4}$ gas (De La Rocha et al., 1996, 1997). IRMS methods have since been improved with $\mathrm{SiF}_{4}$ now produced from acid 
decomposition of $\mathrm{Cs}_{2} \mathrm{SiF}_{6}$ in an automated process employing a modified Kiel III carbonate device and a MAT 252 IRMS (Brzezinski et al., 2006). The first multi-collector inductively coupled plasma mass spectrometer MC-ICP-MS (Nu Plasma ${ }^{\mathrm{TM}}, \mathrm{Nu}$ Instruments, Wrexham, UK) measurements were performed by De La Rocha (2002). This method was improved by Cardinal et al. (2003), who used a dry-plasma mode and Mg doping to correct for mass bias. These early MC-ICP-MS studies measured $\delta^{29} \mathrm{Si}$ (calculated from ${ }^{29} \mathrm{Si} /{ }^{28} \mathrm{Si}$; c.f. Eqn. 1) to avoid the polyatomic interference of ${ }^{14} \mathrm{~N}^{16} \mathrm{O}^{+}$on $m / z^{30} \mathrm{Si}$, but this interference has since been overcome by the higher resolving power of new instruments, with all current studies reporting $\delta^{30} \mathrm{Si}$ values. However, it is possible to convert between the two values using the relationship $\delta^{29} \mathrm{Si}=0.51 \times$ $\delta^{30} \mathrm{Si}$, assuming pure kinetic isotope fractionation of $\mathrm{Si}$ (cf. Reynolds et al., 2007). $\delta^{30} \mathrm{Si}$ isotope measurements have now been successfully performed on a Neptune and Neptune Plus MC-ICPMS (Thermo FisherTM, Germany, e.g. De La Rocha et al., 2011; Zhang et al., 2015b), various types of MC-ICP-MS produced by $\mathrm{Nu}$ Instruments ${ }^{\mathrm{TM}}$ (Wrexham, UK), including a Nu Plasma (e.g. Cardinal et al., 2005), Nu Plasma HR (e.g. Grasse et al., 2013), and the Nu Plasma 1700

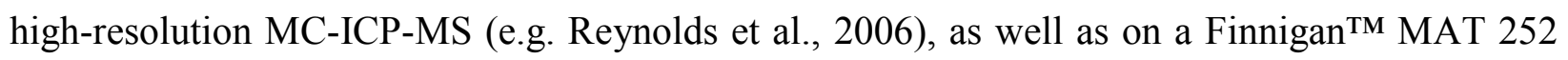
IRMS (e.g. Beucher et al., 2008).

Both mass spectrometry types (MC-ICP-MS and IRMS) produce reliable $\delta^{30} \mathrm{Si}(\mathrm{OH})_{4}$ data with a long-term reproducibility of 0.1 - $0.2 \%$ (2 s. d., e.g. Cardinal et al., 2003; Brzezinski and Jones, 2015). A major advantage of MC-ICP-MS over current IRMS methods is the significantly lower sample mass $(\sim 0.2 \mu \mathrm{mol} \mathrm{Si})$ required for analysis compared to current methods using IRMS that require approximately 10 times higher mass, necessitating a much larger sampling volume which may become prohibitively large for Si-depleted near-surface waters. On the other hand, IRMS measurements have fewer problems with molecular mass interferences, given that $\mathrm{Si}$ is measured in the form of $\mathrm{SiF}_{3}{ }^{+}$at $m / z$ 85, 86, 87. Interference from $\mathrm{SiOF}_{2}$ with ${ }^{29} \mathrm{Si}^{18} \mathrm{OF}_{2}{ }^{+},{ }^{30} \mathrm{Si}^{17} \mathrm{OF}_{2}{ }^{+}$at $m / z 85$ and ${ }^{30} \mathrm{Si}^{18} \mathrm{OF}_{2}{ }^{+}$at $m / z 86$ is possible and can be detected by the presence of the same oxyfluorides containing the far more abundant ${ }^{16} \mathrm{O}$ and ${ }^{28} \mathrm{Si}$ atoms at $m / z$ 82, 83 and 84. Such interferences are rare with current sample preparation methods. With MC-ICP-MS, Si is measured as elemental $\mathrm{Si}$ with potential polyatomic interferences from $\mathrm{C}, \mathrm{H}, \mathrm{O}$ and $\mathrm{N}$ (e.g. ${ }^{14} \mathrm{~N}_{2},{ }^{14} \mathrm{~N}_{2}{ }^{1} \mathrm{H},{ }^{12} \mathrm{C}^{16} \mathrm{O},{ }^{12} \mathrm{C}^{1} \mathrm{H}^{16} \mathrm{O},{ }^{14} \mathrm{~N}^{16} \mathrm{O}$ ) that can bias beam intensities for $m / z{ }^{28} \mathrm{Si},{ }^{29} \mathrm{Si}$ and ${ }^{30} \mathrm{Si}$. Care must also be taken to eliminate matrix effects that may be caused by remnants of dissolved organic matter and anions such as sulfate (van den 
Boorn et al., 2009; Hughes et al., 2011). For a detailed comparison between IRMS and MC-ICPMS measurements see Reynolds et al. (2007).

Recent studies of $\delta^{30} \mathrm{Si}(\mathrm{OH})_{4}$ distribution in deep waters $(>1000 \mathrm{~m})$ in the Atlantic Ocean by de Souza et al. (2012b) and by Brzezinski and Jones (2015) highlight the need for improved intercalibration among laboratories measuring $\delta^{30} \mathrm{Si}(\mathrm{OH})_{4} \cdot \delta^{30} \mathrm{Si}(\mathrm{OH})_{4}$ values at these depths are expected to be invariant over the relatively short period of time separating these studies, yet comparison of $\delta^{30} \mathrm{Si}(\mathrm{OH})_{4}$ data between these two studies showed a near constant offset of approximately $0.22 \%$ between samples of comparable silicic acid concentration (see Figure 2 in Brzezinski and Jones, 2015). Brzezinski and Jones (2015) could not explain the offset, as $\delta^{30} \mathrm{Si}$ values for solid Si standards reported by both laboratories were in good agreement. Given that sample preparation methods for samples of solid and dissolved Si differ considerably (Georg et al., 2006, Reynolds et al. 2006) and in view of the fact that seawater represents a complex matrix of anions and cations, the use of solid standards, and especially of relatively pure siliceous materials, cannot account for sample preparation biases arising during the preparation of seawater samples, motivating the establishment of reference seawaters for this purpose.

The only inter-laboratory calibration of Si isotope standards to date was conducted with solid Si material (Reynolds et al. 2007). In that study, 8 groups participated and obtained consensus mean $\delta^{30} \mathrm{Si}$ values for high-purity $\mathrm{Si}$ solids $\left(\delta^{30} \mathrm{Si}_{\text {Diatomite: }}+1.26 \pm 0.20 \%\right.$ o, $\delta^{30} \mathrm{Si}_{\text {IRMM- }}$ $018:-1.65 \pm 0.22 \%$ o, $\delta^{30} \mathrm{Si}_{\text {Big Batch }}-10.48 \pm 0.54 \%$, uncertainties are 2 s. d.). Those materials are now routinely analyzed and reported when presenting Si isotope data from natural waters, diatom frustules, sponge spicules and minerals. A few rock reference materials are also commonly used as $\delta^{30} \mathrm{Si}$ isotopic standards to determine accuracy and reproducibility of solid samples with a complex matrix, especially BHVO-1 and BHVO-2 (e.g. Abraham et al., 2008; Armytage et al., 2012). As exemplified by the offsets between studies measuring $\delta^{30} \mathrm{Si}(\mathrm{OH})_{4}$ in seawater discussed above, these standards are of limited use for identifying sample preparation biases among laboratories analyzing seawater Si isotopes.

In the following we present the first inter-laboratory calibration study for $\delta^{30} \mathrm{Si}(\mathrm{OH})_{4}$ using seawater samples with low $\left(\sim 9 \mu \mathrm{mol} \mathrm{L}^{-1}\right)$ and high $\left(\sim 113 \mu \mathrm{mol} \mathrm{L}{ }^{-1}\right) \operatorname{Si}(\mathrm{OH})_{4}$ concentration. The two main goals are to evaluate current reproducibility among laboratories and to establish $\delta^{30} \mathrm{Si}(\mathrm{OH})_{4}$ values for the samples so that they can be analyzed and reported as part of future studies to aid in comparing data generated among and within laboratories over time. 


\section{METHODS}

\subsection{Seawater Sampling}

The seawater for the intercalibration study was collected at Station ALOHA $\left(22^{\circ} 45^{\prime} \mathrm{N}\right.$ latitude, $158^{\circ} 00^{\prime} \mathrm{W}$ longitude) in the North Pacific subtropical gyre. Two large volume seawater samples (60 L each) were collected during the Hawaii Ocean Time series (HOT) cruise 256 (October/November 2013) courtesy of the HOT program using the CTD/rosette sampler aboard the $R / V$ Kilo Moana that was equipped with Niskin bottles and a Sea-Bird SBE-9/11 Plus CTD. Samples were collected from $300 \mathrm{~m}\left(\mathrm{ALOHA}_{300}\right)$ and $1000 \mathrm{~m}\left(\mathrm{ALOHA}_{1000}\right)$ water depth in order to obtain samples with a low and with a high $\mathrm{Si}(\mathrm{OH})_{4}$ concentration based on the known increase in $\left[\mathrm{Si}(\mathrm{OH})_{4}\right]$ with depth at this location. For each sample seawater from replicate Niskin bottles was pooled in an acid-washed $(10 \% \mathrm{HCl})$ polyethylene carboy and gravity-filtered into a second acid-washed carboy using AcroPak ${ }^{\circledR}$ filter capsules containing sequential 0.8/0.45 $\mu$ m Supor® membrane filters that had been washed with trace-metal-grade $\mathrm{HCl}$ prior to use. Samples were not acidified or preserved as repeated measures of unpreserved samples show no change in either silicic acid concentration or silicon isotopic composition over a period of ten years when kept in the dark (Brzezinski, unpublished).

\subsection{Sample Preparation and Silicon Isotope Measurements}

At the University of California Santa Barbara (UCSB), the $\mathrm{Si}(\mathrm{OH})_{4}$ concentration of each sample was measured as described by Brzezinski and Nelson (1995). Both ALOHA 300 and $\mathrm{ALOHA}_{1000}$ samples were then aliquoted into $50 \mathrm{~mL}$ acid-cleaned polypropylene screw cap tubes, and shipped in groups of 25 tubes each to participating laboratories.

In total, 11 laboratories from 7 countries participated in the study (Table 1). Each group used its own techniques and protocols for sample preparation and $\mathrm{Si}$ isotope measurements, as detailed in Table A1. In addition to analyzing the seawater samples, many groups also measured the solid secondary standards Big Batch and Diatomite used in the previous intercalibration of siliceous solids by Reynolds et al. (2007).

All groups used some form of scavenging or precipitation to concentrate Si from the $\mathrm{ALOHA}_{300}$ sample and to remove major seawater ions (e.g. $\mathrm{Na}^{+}, \mathrm{Cl}^{-}, \mathrm{SO}_{4}{ }^{2-}$ ). All groups 
followed similar procedures for $\mathrm{ALOHA}_{1000}$ except for group 10 which did not pre-concentrate $\mathrm{ALOHA}_{1000}$. Several pre-concentration methods were used: i) a MAGnesium Induced Coprecipitation (MAGIC) method with sodium hydroxide (Karl and Tien, 1992; Georg et al., 2006, de Souza et al., 2012b); ii) a Mg-induced co-precipitation with purified ammonia $\left(\mathrm{NH}_{3} \cdot \mathrm{H}_{2} \mathrm{O}\right.$, Zhang et al., 2014) and iii) a TEA-Moly precipitation (De La Rocha et al., 1996) during which Si is precipitated as a triethylamine silico-molybdate complex. In the following we will refer to the chemical (NaOH, Ammonia, TEA-Moly) to describe the precipitation method. The most common precipitation method was $\mathrm{NaOH}$, followed by Ammonia and TEA-Moly precipitation.

In order to further purify the samples, most groups using magnesium co-precipitation dissolved the magnesium hydroxide precipitate in a strong acid and then applied column chromatography, using either a cation exchange resin (AG50W-X8; Dowex 50W-X8, AG50W$\mathrm{X} 12,200$ to $400 \mathrm{mesh}$ ) or an anion exchange resin (AG1-X8). Samples precipitated as TEAMoly were purified by high-temperature combustion to solid $\mathrm{SiO}_{2}$ in a platinum crucible, followed by the dissolution of the $\mathrm{SiO}_{2}$ in $\mathrm{HF}$ and the precipitation of the dissolved $\mathrm{Si}$ as $\mathrm{Cs}_{2} \mathrm{SiF}_{6}$ (Brzezinski et al., 2006). Depending on the chemical preparation and the mass spectrometer type, the sample volume needed for $\mathrm{Si}$ isotope measurements ranged from $8 \mathrm{~mL}$ to $2000 \mathrm{~mL}$ for $\mathrm{ALOHA}_{300}$ and from $1 \mathrm{~mL}$ to $200 \mathrm{~mL}$ for $\mathrm{ALOHA}_{1000}$ with the largest seawater volume being required for measurements by IRMS. For an overview of the different chemical preparation methods, see Table 1. More details about chemical preparation and mass spectrometry methods are given in the appendix (Table A1).

$\mathrm{Si}$ isotope measurements were performed on three different mass spectrometer types (Table 1). Four groups used a Neptune or Neptune Plus MC-ICP-MS (Thermo Fisher ${ }^{\mathrm{TM}}$, Germany), six groups a Nu Plasma MC-ICP-MS (Nu Instruments ${ }^{\mathrm{TM}}$, Wrexham, UK; including a $\mathrm{Nu}$ Plasma II MC-ICP-MS and a Nu Plasma 1700 HR-MC-ICP-MS) and one group employed a MAT 252 IRMS (Finnigan ${ }^{\mathrm{TM}}$, now Thermo Fisher ${ }^{\mathrm{TM}}$, Germany). The MC-ICP-MS measurements were performed on solutions containing $10-90 \mu \mathrm{mol} \mathrm{L} \mathrm{L}^{-1} \mathrm{Si}(0.35-2.5 \mathrm{ppm} \mathrm{Si})$, which resulted in a $2-9 \mathrm{~V}$ ion beam (on a Faraday cup equipped with a $10^{11} \Omega$ resistor) for elemental Si with $m / z$ of 28 , the most abundant stable isotope of Si (atom $\%{ }^{28} \mathrm{Si}=92.229 \%$; Rosman and Taylor, 1998). Most MC-ICP-MS analyses were carried out in 'dry plasma mode' using one of three different desolvating nebulizer systems (CETAC Aridus II ${ }^{\mathrm{TM}}$, Nu Instruments DSN-100"T , ESI Apex ${ }^{\mathrm{TM}}$ ) to remove the sample solvent before introduction into the plasma. 
Only 2 groups employed 'wet plasma mode' (Table A1), which avoids possible blank problems with the desolvating nebulizer system, but is less sensitive (De La Rocha, 2002). On the IRMS, samples are loaded into a modified Kiel III carbonate device as solid $\mathrm{Cs}_{2} \mathrm{SiF}_{6}(6 \mu \mathrm{mol} \mathrm{Si})$ and decomposed to $\mathrm{SiF}_{4}$ gas with $98 \%$ sulfuric acid. Electron ionization of $\mathrm{SiF}_{4}$ in the instrument source creates $\mathrm{SiF}_{3}{ }^{+}$ions measured at 85,86 and $87 \mathrm{~m} / z$ (De La Rocha et al. 1996, Brzezinski et al. 2006) with a typical voltage of $4-8 \mathrm{~V}$ (on a Faraday cup with a $3 \times 10^{8} \Omega$ resistor) at $85 \mathrm{~m} / \mathrm{z}$ corresponding to ${ }^{28} \mathrm{Si}^{19} \mathrm{~F}_{3}{ }^{+}$.

The intensity of the blank was generally below $1 \%$ of the sample signal across laboratories (Table A1). All measurements were performed using a standard-sample-bracketing method. For MC-ICP-MS measurements the standard employed was the reference standard NBS28 or an in-house standard that had been calibrated against NBS28. For IRMS measurements samples were run against cryogenically purified commercial $\mathrm{SiF}_{4}$ gas which had been calibrated against NBS28. NBS28 (NIST Reference Material 8546) is a silica sand that was obtained by the United States Geological Survey from the Corning Glass Company.

$\mathrm{Si}$ isotope compositions are reported in the $\delta$-notation using the reference standard NBS28 in parts per thousand,

$$
\delta^{30} S i=\left(\left(\frac{R_{\text {sample }}}{R_{\text {std }}}\right)-1\right) * 1000
$$

where $R_{\text {sample }}$ is the measured ${ }^{30} \mathrm{Si} /{ }^{28} \mathrm{Si}$ ratio of the sample and $R_{\text {std }}$ is the measured ${ }^{30} \mathrm{Si} /{ }^{28} \mathrm{Si}$ ratio of the NBS28 standard.

Laboratories pre-concentrated each seawater sample 3 to 10 times. Each preconcentration was considered to be a replicate when performing statistical tests and when evaluating the external reproducibility for each group (2 s. d., Table 2, A2). The analytical scheme applied to each pre-concentration was as follows: Subsamples of each concentrate were analyzed between 1 and 12 times with the actual number of analyses performed listed as analytical replicates for each pre-concentration in Table A2. Analysis of the subsamples by both IRMS and MC-ICP-MS utilized a standard-sample-bracketing approach, which depending on the laboratory involved 15 to 60 measurements of the subsample bracketed by analyses of the standard. Each set of analytical replicates was averaged providing a mean value for each separate pre-concentration of $\mathrm{ALOHA}_{300}$ and of $\mathrm{ALOHA}_{1000}$ performed by each laboratory (Table A2). 
Analysis of variance (ANOVA) was used to test for difference among means with post hoc tests performed using Tukey's HSD (honest significant difference) method to control type I error rate across multiple comparisons. For each ANOVA Levene's method was used to test for the equality of variance among factors and the Shapiro-Wilk method was used to test that the residuals from each ANOVA model were normally distributed. A significance level of $\mathrm{p}=0.05$ was used throughout. Residuals were normally distributed across all tests and will not be discussed further. However, in some cases the variance across factors was found not to be constant. In those cases, differences among means were re-evaluated using Welch's ANOVA that is not reliant on an assumption of homogenous variances among factors with post hoc testing performed using False Discovery Rate procedures (q-FDR, e.g. Benjamini and Hochberg, 1995; Verhoevenetal., 2005). q-FDR controls the expected proportion of type I errors rather than the probability that such errors will occur which can increase statistical power compared to familywise error rate techniques for handling multiple comparisons (Benjamini and Hochberg, 1995). Statistical analyses were performed using JMP 12 statistical software.

\subsection{Mg Doping and Sulfate Addition}

Except for one laboratory, all measurements on Neptune mass spectrometers were performed with $\mathrm{Mg}$ doping of the sample, whereas only group 10 applied $\mathrm{Mg}$ doping to samples measured on a Nu Plasma instrument. Cardinal et al. (2003) showed that Mg isotope mass bias is constant relative to $\mathrm{Si}$ isotopes during a MC-ICP-MS analytical session and follows an exponential mass fractionation law. Si isotope ratios $\left({ }^{30} \mathrm{Si} /{ }^{28} \mathrm{Si}\right.$ and $\left.{ }^{29} \mathrm{Si} /{ }^{28} \mathrm{Si}\right)$ were corrected for mass bias by adding $\mathrm{Mg}\left(\mathrm{NO}_{3}\right)_{2}$ to samples and to standards just prior to measurement (Cardinal et al., 2003; Abraham et al., 2008). Mg is added at a concentration that matches the Si content of standards and samples. Between each measurement of Si isotopes ${ }^{24} \mathrm{Mg}$ and ${ }^{25} \mathrm{Mg}$ and/or ${ }^{26} \mathrm{Mg}$ isotopes are measured in dynamic mode with the same integration time as for $\mathrm{Si}$ isotopes. The correction to the ${ }^{30} \mathrm{Si} /{ }^{28} \mathrm{Si}$ ratio $\left({ }^{30} \mathrm{Si} /{ }^{28} \mathrm{Si}\right)$ corr is calculated as follows:

$$
\left({ }^{30} \mathrm{Si} /{ }^{28} \mathrm{Si}\right)_{\mathrm{corr}}=\left({ }^{30} \mathrm{Si} /{ }^{28} \mathrm{Si}\right)_{\text {meas }} \times\left({ }^{30} \mathrm{Si}_{\mathrm{AM}} /{ }^{28} \mathrm{Si} \mathrm{AM}_{\mathrm{AM}}\right)^{\varepsilon}
$$

where $\left({ }^{30} \mathrm{Si} /{ }^{28} \mathrm{Si}\right)_{\text {meas }}$ is the measured ratio, ${ }^{30} \mathrm{Si}_{\mathrm{AM}}$ and ${ }^{28} \mathrm{Si}_{\mathrm{AM}}$ are the atomic masses of ${ }^{30} \mathrm{Si}$ and ${ }^{28} \mathrm{Si}$. $\varepsilon_{\mathrm{Mg}}$ is then calculated from the beam intensities on masses 26 and 24 as: 


$$
\varepsilon_{\mathrm{Mg}}=\ln \left[\left({ }^{26} \mathrm{Mg}_{\mathrm{A}} /{ }^{24} \mathrm{Mg}_{\mathrm{A}}\right) /\left({ }^{26} \mathrm{Mg} /{ }^{24} \mathrm{Mg}\right)_{\text {meas }}\right] /\left[{ }^{26} \mathrm{Mg}_{\mathrm{AM}} /{ }^{24} \mathrm{Mg}_{\mathrm{AM}}\right]
$$

where ${ }^{26} \mathrm{Mg}_{\mathrm{A}} /{ }^{24} \mathrm{Mg}_{\mathrm{A}}$ is the expected ratio of the natural abundances of the isotopes, $\left({ }^{26} \mathrm{Mg} /{ }^{24} \mathrm{Mg}\right)_{\text {meas }}$ is the measured ratio, and ${ }^{26} \mathrm{Mg}_{\mathrm{AM}}$ and ${ }^{24} \mathrm{Mg}_{\mathrm{AM}}$ are the atomic masses of ${ }^{26} \mathrm{Mg}$ and ${ }^{24} \mathrm{Mg}$.

One laboratory (group 2) implemented sulfate doping to overcome the effects of the presence of seawater sulfate ions (Table 1). Van den Boorn et al. (2009) first reported a significant isotopic bias due to the presence of $\mathrm{SO}_{4}{ }^{2-}$ in rock samples after a cation chromatographic purification step. Such a bias was also observed by Hughes et al. (2011) on freshwater samples of dissolved Si, although Georg et al. (2006) and de Souza et al. (2012b) observed no significant matrix effect of $\mathrm{SO}_{4}{ }^{2-}$ on their MC-ICP-MS analyses of Si isotopes from freshwater and seawater samples. In the present study several tests were made to optimize sulfate doping. For group 2, systematic and constant $\mathrm{H}_{2} \mathrm{SO}_{4}$ additions were performed as for $\mathrm{Mg}$ prior to the measurements on the ALOHA 1000 sample and the NBS28 standard at $1 \mathrm{mmol} \mathrm{L}^{-1}$, which should largely overcome the amount of seawater $\mathrm{SO}_{4}{ }^{2-}$ remaining in the solutions. For the $\mathrm{ALOHA}_{300}$ sample where group 2 processed $50 \mathrm{~mL}$ of seawater, systematic measurements of $\mathrm{SO}_{4}{ }^{2-}$ were made via ad-hoc doping to reach $1 \mathrm{mmol} \mathrm{L}^{-1} \mathrm{H}_{2} \mathrm{SO}_{4}$. Nitric acid and $\mathrm{HCl}$ were also added by group 2 to all samples and standards to reach final concentrations of $0.5 \mathrm{~mol} \mathrm{~L}^{-1}$ each in order to overcome the influence of residual seawater nitrate and chloride ions.

One laboratory (group 1) treated samples with ultraviolet light/ozone to remove dissolved organic carbon (DOC; Table 1) as Hughes et al. (2011) revealed significant biases in $\delta^{30} \mathrm{Si}$ data when DOC concentrations significantly exceeded those of dissolved Si.

\section{Results}

The seawater samples collected from $300 \mathrm{~m}$ (300.21 decibar pressure, $13.37^{\circ} \mathrm{C}$, salinity 34.311) and $1000 \mathrm{~m}$ (1021.65 decibar pressure, $3.88^{\circ} \mathrm{C}$, salinity 34.467$)$ at Station ALOHA resulted in the desired range of $\mathrm{Si}(\mathrm{OH})_{4}$ concentrations with measured concentrations of $9.18 \pm$ $0.05 \mu \mathrm{mol} \mathrm{L}^{-1}$ and $112.8 \pm 0.5 \mu \mathrm{mol} \mathrm{L}^{-1}$ for $\mathrm{ALOHA}_{300}$ and $\mathrm{ALOHA}_{1000}$, respectively.

In total, 11 laboratory groups participated in the seawater intercalibration study. The $\delta^{30} \mathrm{Si}(\mathrm{OH})_{4}$ values for $\mathrm{ALOHA}_{300}$ and $\mathrm{ALOHA}_{1000}$ from each laboratory were in good overall agreement. Average values from individual laboratories for $\mathrm{ALOHA}_{300}$ ranged from $+1.46 \%$ to 
$+1.94 \%$, with a mean value of $+1.68 \pm 0.35 \%$ ( 2 s. d., results from 9 groups $). \delta^{30} \mathrm{Si}(\mathrm{OH})_{4}$ values for $\mathrm{ALOHA}_{1000}$ ranged between $+1.10 \%$ and $+1.45 \%$ with a mean of $+1.24 \pm 0.20 \%$ (2 s. d., results from 11 groups; Fig. 1, Table 2). Normal probability plots of the laboratory group means for each sample were highly linear with $\mathrm{R}^{2} \geq 0.95$ (Fig. 2). Shapiro's tests confirmed that the group averages for $\mathrm{ALOHA}_{300}$ were normally distributed $\left(\mathrm{W}=0.966, \mathrm{p}=0.21\right.$, where $\mathrm{H}_{0}$ is that the data are fromm a normal distribution); however, group means for ALOHA 1000 were not $(\mathrm{W}=0.954, \mathrm{p}=0.036)$. In the latter case the median or modal value may be better measures of central tendency. Median values and interquartile deviations, i.e. 0.5 x (75\% quartile - 25\% quartile), for $\mathrm{ALOHA}_{300}$ and $\mathrm{ALOHA}_{1000}$, are $+1.66 \pm 0.13 \%$ and $+1.25 \pm 0.06 \%$ respectively (Table 2) with corresponding modal values of 1.66 and 1.22. Values obtained for Big Batch and Diatomite by each group that measured these materials (Table A3) were within the uncertainty bounds of the values established by Reynolds et al. (2007).

The reproducibility of measurements for the seawater samples within individual groups ranged from $0.04 \%$ to $0.24 \%$ for the standard deviations and $0.06 \%$ to $0.13 \%$ for the interquartile deviations with the larger variation generally obtained for $\mathrm{ALOHA}_{300}$ (Fig. 1, Table 2). For each sample testing for statistically significant differences in the mean isotope values obtained by each group is confounded as all groups used a single mass spectrometer type negating the use of a two-way ANOVA to simultaneously test for differences among groups and among mass spectrometer types. Testing for differences in the mean isotope values across groups was thus restricted to tests among laboratories using the same mass spectrometer type. Tests for differences among sample preparations methods reveal no significant sample preparation effect (see below) so the effect of preparation was subsumed in the mean square error when examining differences among laboratory groups.

Considering groups that used a Neptune mass spectrometer the ANOVA revealed significant differences among mean values across groups for $\operatorname{ALOHA}_{1000}(\mathrm{~F}=27.2$, d. f. $=3, \mathrm{p}<$ 0.001), but not for $\mathrm{ALOHA}_{300}(\mathrm{~F}=0.30$, d.f. $=1, \mathrm{p}=0.59$, note only two groups measured $\mathrm{ALOHA}_{300}$ using a Neptune) indicating the presence of small, but statistically significant, biases between laboratories for ALOHA $_{1000}$. However, Levene's test showed unequal variances across groups for both $\mathrm{ALOHA}_{300}(\mathrm{~F}=8.85$, d.f. $=1, \mathrm{p}=0.012)$ and for $\operatorname{ALOHA}_{1000}(\mathrm{~F}=3.35$, d.f. $=3$, $\mathrm{p}=0.045$ ) so that the results of the ANOVA should be interpreted with caution. When these data were re-evaluated using Welch's ANOVA the presence of significant differences among 
means for $\mathrm{ALOHA}_{1000}(\mathrm{~F}=38.2$, d.f. $=3, \mathrm{p}<0.0004)$ and the lack of any significant differences among groups for $\mathrm{ALOHA}_{300}(\mathrm{~F}=0.374$, d.f. $=1, \mathrm{p}=0.55)$ were confirmed. Post hoc tests (Table A4) revealed that differences among laboratories were not consistent between the two seawater samples.

A similar analysis investigating differences among groups using $\mathrm{Nu}$ Plasma mass spectrometers showed significant differences among means for both $\operatorname{ALOHA}_{300}(\mathrm{~F}=34.5$, d.f. $=$ $5, \mathrm{p}<0.001)$ and $\mathrm{ALOHA}_{1000}(\mathrm{~F}=6.90$, d.f. $=5, \mathrm{p}=0.0004)$. In both cases the assumption of equality of variances was met (Levine: $\mathrm{F}=0.765$, d.f. $=5, \mathrm{p}=0.58$ and $\mathrm{F}=0.421$, d.f. $=5, \mathrm{p}=$ 0.83 for $\mathrm{ALOHA}_{1000}$ and $\mathrm{ALOHA}_{300}$, respectively). Similar to the case for the Neptune, post hoc tests (Table A5) showed that the pattern of significant differences among group means for the $\mathrm{Nu}$ Plasma shifted between $\mathrm{ALOHA}_{300}$ and $\mathrm{ALOHA}_{1000}$. The shifting biases among groups seen for both instruments is also seen in the change in rank order of the mean isotope values obtained by each group between the $\mathrm{ALOHA}_{1000}$ and $\mathrm{ALOHA}_{300}$ samples (Fig. 1).

An indicator for the quality of $\delta^{30} \mathrm{Si}$ measurements is given by the slope of the relationship between $\delta^{30} \mathrm{Si}$ and $\delta^{29} \mathrm{Si}$ values, as any polyatomic interferences during MC-ICP-MS measurements would lead to an offset from predicted equilibrium or kinetic fractionation line. Least squares linear regression between $\delta^{30} \mathrm{Si}(\mathrm{OH})_{4}$ and $\delta^{29} \mathrm{Si}(\mathrm{OH})_{4}$ produces a slope of $0.5188 \pm$ 0.0184 (s.e., $\mathrm{R}^{2}=0.98$; Fig. 3). Repeating the analysis using reduced major axis model II regression that gives equal weight to errors in both $\delta^{29} \mathrm{Si}(\mathrm{OH})_{4}$ and $\delta^{30} \mathrm{Si}(\mathrm{OH})_{4}$ yields a slope of $0.5131 \pm 0.0040$ (s.e., $\mathrm{R}^{2}=0.98$ ).

Figure 4 shows the $\delta^{30} \mathrm{Si}(\mathrm{OH})_{4}$ data for all measurements grouped by mass spectrometer type (Fig. 4a, 4b) and by co-precipitation method (Fig. 4c, 4d). Considering mass spectrometer types the Neptune and $\mathrm{Nu}$ Plasma types are replicated across groups while the IRMS is not as IRMS was used by a single group. Thus statistical analysis of mass spectrometer type was only possible for Neptune and $\mathrm{Nu}$ Plasma types. Furthermore, as each laboratory used a single mass spectrometer the data from the same group are not independent. To account for this lack of independence an ANOVA with Neptune and Nu Plasma as main effects was performed on the average values obtained by each group weighted by the number of measurements contributing to each mean. Those results show no significant differences between the results obtained on the Neptune versus the $\mathrm{Nu}$ Plasma for $\operatorname{ALOHA}_{300}(\mathrm{~F}=0.687$, d.f. $=1, \mathrm{p}=0.44)$ and likewise for $\operatorname{ALOHA}_{1000}(\mathrm{~F}=3.75$, d.f. $=1, \mathrm{p}=0.089)$. In qualitative terms the values obtained by IRMS are 
nearly identical to those obtained using the $\mathrm{Nu}$ Plasma for $\mathrm{ALOHA}_{1000}$, but they appear lower than the averages for either the $\mathrm{Nu}$ Plasma or Neptune for $\mathrm{ALOHA}_{300}$. That difference is driven by one low value of $+1.36 \%$ measured by IRMS (Table A2). If that value is considered an outlier the resulting mean for IRMS becomes closer to that for the other two mass spectrometer types, $+1.52 \%$ (Figure 4 ).

ANOVAs evaluating the effect of different precipitation methods showed no differences among $\mathrm{NaOH}$, Ammonia or TEA-moly procedures for $\mathrm{ALOHA}_{1000}(\mathrm{~F}=0.27$, d. f. $=2, \mathrm{p}=0.77)$, but a significant difference for $\operatorname{ALOHA}_{300}(\mathrm{~F}=4.7$, d. f. $=2, \mathrm{p}=0.014)$ driven by a lower mean value for TEA-moly precipitation compared to the other two methods (Table 3, Figure 4). For $\mathrm{ALOHA}_{300}$ the significant differences between precipitation methods are driven by one outlier value mentioned above (Table A2). When that value is removed from the analysis no significant differences among precipitation methods $(\mathrm{F}=2.4$, d. f. $=2, \mathrm{p}=0.10)$ are found for $\mathrm{ALOHA}_{300}$. We are quick to point out that the ANOVA used to detect differences among precipitation methods necessarily incorporated the effects of groups and of mass spectrometer type into the mean square error as the experimental design is confounded so that these results should be viewed with caution. One group, Group 6, utilized both $\mathrm{NaOH}$ and Ammonia co-precipitation methods allowing a direct comparison of methods for this one group. Here too there was no significant difference between precipitation methods $(F=0.61$, d.f. $=1, p=0.49)$.

\section{Discussion}

\subsection{General Results}

We present the first inter-laboratory study comparing the stable silicon isotope composition of dissolved $\mathrm{Si}(\mathrm{OH})_{4}$ in seawater. Samples with both a relatively low and a relatively high $\mathrm{Si}(\mathrm{OH})_{4}$ concentration were used to evaluate the influence of varying degrees of Si pre-concentration and varying matrix to analyte ratios. The results from the 11 laboratories were in good agreement for both samples, despite the use of different sample preparation and purification methods and different mass spectrometer models (Nu Plasma versus Neptune) and types (MC-ICP-MS versus IRMS). The mean $\delta^{30} \mathrm{Si}(\mathrm{OH})_{4}$ values for $\mathrm{ALOHA}_{300}$ and $\mathrm{ALOHA}_{1000}$ were $+1.68 \pm 0.35 \%$ and $+1.24 \pm 0.20 \%$ ( 2 s. d.), respectively (Fig. 1, Table 2 ). Given that the data for $\mathrm{ALOHA}_{1000}$ are not normally distributed a better representation of the central tendency is the median. Median values and interquartile deviations for $\mathrm{ALOHA}_{300}$ and $\mathrm{ALOHA}_{1000}$, are 
$+1.66 \pm 0.13 \%$ and $+1.25 \pm 0.06 \%$ respectively (Table 2$)$. Modal values are nearly identical (within $0.03 \%$ ) of corresponding median values (Table 2).

The slope of the least squares fit of $\delta^{30} \mathrm{Si}(\mathrm{OH})_{4}$ versus $\delta^{29} \mathrm{Si}(\mathrm{OH})_{4}$ relationship, 0.5188 is statistically indistinguishable from the theoretical value of 0.5178 for equilibrium control of fractionation $(\mathrm{t}=0.302$, d. $\mathrm{f} .=19, \mathrm{p}=0.38$; Thiemens, 1999, Young et al. 2002) and significantly higher than those for kinetic fractionation, i.e. 0.5047 or 0.5092 depending on whether elemental $\mathrm{Si}$ or $\mathrm{SiO}_{2}$ is fractionating, respectively $(\mathrm{t}=4.26$, d. f. $=19, \mathrm{p}=<0.0001$ for $\mathrm{Si}$ and $\mathrm{t}=2.90$, d. $\mathrm{f}$. $=19, \mathrm{p}<0.0001$ for $\mathrm{SiO}_{2}$, Young et al. 2002). The slope of the reduced major axis regression, 0.5131 , is statistically indistinguishable from both the theoretical value for equilibrium fraction $(\mathrm{t}$ $=1.17, \mathrm{~d} . \mathrm{f} .=19, \mathrm{p}=0.13)$ and the kinetic fractionation of $\mathrm{SiO}_{2}(\mathrm{t}=0.94, \mathrm{~d} . \mathrm{f} .=19, \mathrm{p}=0.97)$, but it was statistically larger than the theoretical value for the kinetic fractionation of elemental $\mathrm{Si}(\mathrm{t}=2.10, \mathrm{~d} . \mathrm{f} .=19, \mathrm{p}<0.00001)$. For reference the Bonferroni corrected $\mathrm{p}$ value for these six comparisons is 0.008 . Thus, the data lack the precision necessary to discriminate between control by equilibrium or kinetic fractionation. Ultimately, the fractionation of $\mathrm{Si}(\mathrm{OH})_{4}$ in the sea should be kinetically controlled given the strong role of biology in the process (Nelson et al.1995).

The tight relationship between $\delta^{30} \mathrm{Si}(\mathrm{OH})_{4}$ and $\delta^{29} \mathrm{Si}(\mathrm{OH})_{4}$ relationship does indicate insignificant isobaric interference problems during $\mathrm{Si}$ isotope analysis. External reproducibility ( 2 s. d.) during this study (0.20\%o and $0.35 \%$ for $\mathrm{ALOHA}_{1000}$ and $\mathrm{ALOHA}_{300}$, respectively) were similar to those obtained during the inter-laboratory comparison of $\mathrm{Si}$ isotopes in pure siliceous solid materials by Reynolds et al. (2007), where 2 s. d. uncertainty values of $0.22 \%$, $0.16 \%$ and $0.54 \%$ were obtained for the standards IRMM-018, Diatomite and Big Batch, respectively. Analyzing both $\mathrm{ALOHA}_{300}$ and $\mathrm{ALOHA}_{1000}$ as a routine part of future studies of seawater Si isotopes will allow potential biases to be quantified, facilitating comparisons among data sets.

The suite of methodologies used to analyze the isotopic composition of $\mathrm{Si}$ in the seawater samples all yielded robust results. Comparison of the data obtained from the low and high concentration samples suggests that further improvement may be possible. Overall $\mathrm{ALOHA}_{1000}$ shows a better reproducibility ( \pm 0.20 \%o s.d., $0.05 \%$ i.q.d) than $\mathrm{ALOHA}_{300}( \pm 0.35$ \%o s.d., 0.13 \%o i.q.d.) among laboratories and within each laboratory (Fig. 1, Table 2). Small, but statistically significant, differences in the mean isotope values among laboratories were 
detected for both samples (Table A4). Moreover, the number and magnitude of significant differences changed between the low and high concentration samples (Table A4). Together these results imply that differences in how the two samples were processed marginally influenced the results.

The main difference in sample preparation between $\mathrm{ALOHA}_{300}$ and $\mathrm{ALOHA}_{1000}$ was the larger sample volume processed for $\mathrm{ALOHA}_{300}$ (Table A1). The volume of seawater used for pre-concentration scales inversely with the $\mathrm{Si}(\mathrm{OH})_{4}$ concentration in the sample such that larger volumes are processed for samples with low Si concentration. To the extent that they are not removed during the chromatographic purification of $\mathrm{Si}$, the carryover of seawater ions (e.g. $\mathrm{Mg}^{2+}, \mathrm{Na}^{+}, \mathrm{Ba}^{2+}, \mathrm{Cl}^{-}, \mathrm{SO}_{4}{ }^{2-}$ ) will be a function of the sample volume processed, altering the ratio of these ions to the analyte $\mathrm{Si}$ in the final sample which may produce matrix effects during measurements (see Methods). As most groups use a cation exchange resin as the final purification step (Table 1), residual anions are likely present.

Another possible cause of the larger variance of the measurements of $\mathrm{ALOHA}_{300}$ could be the higher DOC to Si ratio in the shallow sample. Any element remaining in the solution analyzed can compete with analyte for ionization within the plasma and thus can potentially induce a matrix effect on isotopic mass bias. Hughes et al. (2011) showed that a DOC:Si mass ratio (as C:Si) above 0.6 can interfere with $\delta^{30} \mathrm{Si}$ measurements. DOC concentrations measured on the same cruise and at the same depths as sampled for Si isotopes were 48 and $37 \mu \mathrm{mol} \mathrm{C} \mathrm{L}{ }^{-1}$ for $\mathrm{ALOHA}_{300}$ and $\mathrm{ALOHA}_{1000}$, respectively (C. A. Carlson, pers. com.), which are three orders of magnitude lower than in the samples analyzed by Hughes et al. (2011). However, DOC/Si mass ratios $(\mathrm{C} / \mathrm{Si})$ were 2.2 and 0.1 for $\mathrm{ALOHA}_{300}$ and $\mathrm{ALOHA}_{1000}$, respectively. Those ratios imply a potential for interference from DOC in $\mathrm{ALOHA}_{300}$ if DOC is concentrated at the same efficiency as Si during the sample pre-concentration procedure. Detailed investigations into these and other possible interferences may improve the analytical precision obtained for low concentration samples.

\subsection{Potential Instrument Biases}

Measurements on the Neptune (mean $=+1.18 \pm 0.18 \%$ ) and the $\mathrm{Nu}$ Plasma (mean $=+1.28 \pm$ $0.18 \%$ ) show a slight and only marginally significant $(\mathrm{p}=0.089)$ offset for $\mathrm{ALOHA}_{1000}$ with the values from the Neptune being lower by $0.1 \%$. For $\mathrm{ALOHA}_{300}$ the mean value on the Neptune 
is also lower than on the $\mathrm{Nu}$ Plasma by $0.1 \%$ (Table 3), but in this case the difference is far from statistically significant given the larger variance of the measurements for the shallow sample. One possible explanation for this offset could be the applied $\mathrm{Mg}$ doping of the sample, which is mainly conducted for measurements on the Neptune (except for group 11), to correct for the instrumental mass bias (Cardinal et al. 2003). This possibility was investigated by examining the results for Group 11, which performed Si isotope analysis on a Neptune without Mg doping. The mean value for this group was slightly higher $+1.27 \pm 0.05 \%$ (2s.d.), than the Neptune mean. Only one group (Group 10) applied $\mathrm{Mg}$ doping using a $\mathrm{Nu}$ Plasma, which resulted in a mean value of $+1.45 \pm 0.17 \%$, higher than the average $\delta^{30} \mathrm{Si}$ value of $+1.28 \pm 0.18 \%$ obtained by groups using the $\mathrm{Nu}$ Plasma without Mg doping. The results are thus inconclusive, and it is not clear whether $\mathrm{Mg}$ doping or an instrument bias caused the small offset between the results from the Neptune and Nu Plasma instruments.

The average $\delta^{30} \mathrm{Si}(\mathrm{OH})_{4}$ value from IRMS match the average from the $\mathrm{Nu}$ Plasma for $\mathrm{ALOHA}_{1000}$, but they are lower than both the Nu Plasma or Neptune data for ALOHA 300 . It is difficult to draw firm conclusions from these similarities and differences given the very large difference in the volume of seawater processed for measurement by IRMS compared to the other instrument types (Table 3).

\subsection{Possible Improvement of Chemical Preparation and $\delta^{30}$ Si Measurements}

There are several approaches to reduce "matrix effects" in MC-ICP-MS measurements caused by remnants of DOC and seawater ions in samples (Cardinal et al., 2007, Hughes et al., 2011). Methods that further reduce the ion concentrations (cations and anions) may thus be beneficial or ion concentrations in the sample solution could be measured and the samples doped prior to measurement, though the latter may be cumbersome for studies with large numbers of samples. Alternatively, a sequential cation-anion-exchange chromatography purification procedure, such as has been tested by some groups for $\delta^{30} \mathrm{Si}(\mathrm{OH})_{4}$ (N. Estrade, pers. comm.), may be a promising approach. Closset (2015) showed that the contribution of $\mathrm{Cl}^{-}$originating from seawater can be neglected when $\mathrm{HCl}$ is used to dissolve the brucite produced during $\mathrm{Mg}$ coprecipitation as the $\mathrm{Cl}^{-}$from the acid is present in large excess (up to $0.5 \mathrm{~mol} \mathrm{~L}^{-1}$ ) compared to remaining $\mathrm{Cl}^{-}$from seawater. Similarly, the occurrence of $\mathrm{NO}_{3}{ }^{-}$in seawater is negligible when $\mathrm{HNO}_{3}\left(0.5 \mathrm{~mol} \mathrm{~L}{ }^{-1}\right)$ is used as a solvent in both the samples and standards. In the present study 
group 2 employed a mixture that was $0.5 \mathrm{~mol} \mathrm{~L}^{-1} \mathrm{HCl}, 0.5 \mathrm{~mol} \mathrm{~L}^{-1} \mathrm{HNO}_{3}$ and $1 \mathrm{mmol} \mathrm{L}^{-1} \mathrm{H}_{2} \mathrm{SO}_{4}$ to simultaneously compensate for the presence of $\mathrm{Cl}^{-}, \mathrm{NO}_{3}{ }^{-}$and $\mathrm{SO}_{4}{ }^{2-}$.

The concentration of $\mathrm{SO}_{4}{ }^{2-}$ ions remaining after chemical purification of the $\mathrm{Si}$ (i.e. not collected by cation exchange resin) depends on the volume of seawater used for the $\mathrm{NaOH}$ and Ammonia methods. There is, however, no simple relationship between total sample volume processed and final $\mathrm{SO}_{4}{ }^{2-}$ concentration, since most seawater is discarded during the preconcentration procedure. Some laboratories also observed that the presence of high $\mathrm{SO}_{4}{ }^{2-}$ (higher than $0.5 \mathrm{mmol} \mathrm{L}^{-1}$ ) may cause a negative shift in the baseline of ${ }^{29} \mathrm{Si}$ and ${ }^{30} \mathrm{Si}$ due to the high ${ }^{32} \mathrm{~S}$ signal. More importantly, this impact will directly alter the $\mathrm{Si}^{+}$signal intensity and is different from the matrix effect, and cannot be corrected using the matrix-match approach (Zhang A., data unpublished). The influence of residual ions also varies with the number of coprecipitations employed as the two-step $\mathrm{NaOH}$ process developed by Reynolds et al. (2006) significantly reduces the final seawater volume from which Si is stripped compared to a one step co-precipitation. Furthermore, a general treatment of seawater sample with ultra violet light, ozone or peroxide to reduce the influence of dissolved organic matter, as already suggested by Hughes et al. (2011) may be beneficial.

The IRMS method is largely free of "matrix effects". Interference from $\mathrm{SiOF}_{2}$ is rare as a significant signal at $m / z 83$ that would indicate the presences of the compound (see above) are rarely observed. The major challenge with the $\mathrm{Cs}_{2} \mathrm{SiF}_{6}$ IRMS method is the large sample size required compared to $\mathrm{MC}$-ICP-MS. When less than $5 \mu$ moles of $\mathrm{Cs}_{2} \mathrm{SiF}_{6}$ are analyzed the resulting $\delta^{30} \mathrm{Si}$ values are significantly biased to higher values (Brzezinski et al., 2006). This is not a limitation of the instrument, as the Kiel III/ MAT 252 combination is capable of analyzing at least an order of magnitude lower amount of Si. The reason for the apparent fractionation of small samples is unknown. Overcoming this limitation would allow seawater sample volumes similar to those currently employed for MC-ICP-MS analysis. The lower limit of sample size would then essentially only be determined by the mass of Si necessary to quantitatively precipitate $\mathrm{Cs}_{2} \mathrm{SiF}_{6}$.

\subsection{Best Practices during MC-ICP-MS Measurements}

The major challenges during MC-ICP-MS measurements leading to lower accuracy and precision are i) molecular interference at $m / z{ }^{28} \mathrm{Si}\left({ }^{14} \mathrm{~N}_{2},{ }^{12} \mathrm{C}{ }^{16} \mathrm{O}\right),{ }^{29} \mathrm{Si}\left({ }^{14} \mathrm{~N}_{2}{ }^{1} \mathrm{H},{ }^{12} \mathrm{C}^{1} \mathrm{H}^{16} \mathrm{O}^{15} \mathrm{~N}^{14} \mathrm{~N}\right)$ 
and ${ }^{30} \mathrm{Si}\left({ }^{14} \mathrm{~N}^{16} \mathrm{O}\right)$ and ii) variable mass-dependent fractionation in the instrument (mass-bias, see also Cardinal et al. 2003). To handle possible problems with interfering compounds the matrix blank should not exceed $1 \%$ of the sample sensitivity and it should be routinely measured and subtracted from the measurement signal. Furthermore the achieved resolving power (10\% peak valley definition) of the mass spectrometer should be above 3500 in order to clearly separate molecular interference masses. All of these issues are also influenced by operating condition ("plasma conditions"), non-analyte composition of the particular sample ("matrix effect") and the amount of material that is introduced into the instrument ("mass-load effect"), which is determined by the Si concentration introduced into the instrument by the sample gas flow. A study by Zhang et al. (2015b) also demonstrated that the sample gas flow has an effect on the production of polyatomic ions besides its obvious effects on sensitivity and stability. The importance of the energetic/thermal "plasma conditions" during ICP-MS measurements for precise and accurate stable isotope measurements was recently shown by Fietzke et al. (2015). Therefore, in addition to the elemental purity of the sample and the Si concentration introduced into the instrument, plasma conditions should be monitored carefully in order to improve the accuracy and precision of $\delta^{30} \mathrm{Si}$ measurements. This may require allowing the instrument to stabilize for several hours before measurements.

\subsection{Recommendations}

The intercalibration results show a very good precision within all participating groups taking into account the external reproducibility of the individual measurements. However, small but statistically significant differences among mean values across groups were observed for both samples. Such differences can be rigorously quantified through routine analysis of these reference waters as part of future studies of $\delta^{30} \mathrm{Si}(\mathrm{OH})_{4}$ distributions in the ocean. This is particularly important for international programs such as GEOTRACES for which global data from multiple laboratories are often combined for analysis. It is recommended that future studies analyzing $\delta^{30} \mathrm{Si}(\mathrm{OH})_{4}$ in seawater also analyze $\mathrm{ALOHA}_{300}$ and $\mathrm{ALOHA}_{1000}$ and report these results to facilitate and evaluate comparability of data between laboratories. While the use of ALOHA samples is needed to validate the seawater processing procedures, analytical conditions and instrument stability should first be checked for each analytical session by measuring secondary reference materials such as Diatomite and Big Batch (Reynolds et al., 2007) which are 
more readily available. ALOHA samples, Diatomite and Big Batch can be obtained from Mark Brzezinski at UCSB. Finally, a plan for reference water renewal must be developed to facilitate intercalibration efforts in the future.

\section{Acknowledgements}

Our thanks to Matthew Church for his help in obtaining seawater samples from Hawaii Ocean Time Series station ALOHA. This work was supported by OCE-1233029 from the US National Science Foundation, Chemical Oceanography Program to MB. DC thanks for their financial support the EU FP7 (CIG \#294146) and IPSL. GFDS is funded by a Marie Skłodowska-Curie Research Fellowship under EU Horizon2020 (SOSiC, GA \#708407). PG and MF acknowledge funding by the Collaborative Research Centre 754 "Climate- Biogeochemistry interactions in the Tropical Ocean" (www.sfb754.de), supported by the Deutsche Forschungsgemeinschaft (DFG). The work by JNS was supported by the "Laboratoire d'Excellence" LabexMER (ANR-10-LABX-19) and co-funded by a grant from the French government under the program "Investissements d'Avenir", and by a grant from the Regional Council of Brittany (SAD programme). AZ and JZ were supported by the Ministry of Science and Technology of China (grant 2011CB409801). QL and DL acknowledge financial support from the National Natural Science Foundation of China (No. 21422509 and 91543104). RF and DW acknowledge financial support from the Natural Sciences and Engineering Research Council of Canada and NE benefitted from a post-doctoral fellowship from NSERC (CREATE MAGNET). CE and KP acknowledge the funding from ICBM (Univ. of Oldenburg) and the Max Planck Institute for Marine Microbiology Bremen. ). PA, EK and MS acknowledge the financial support of Vetenskapsrådet, Sweden, for funding the Vegacenter at NRM Stockholm (grant \#829-2011-6326). We also would like to acknowledge William Rice and Wilfried Rickels for the improvement of the statistics. 


\section{References}

Abraham, K., Opfergelt, S., Fripiat, F., Cavagna, A.-J., De Jong, J. T. M., Foley, S. F., et al. (2008). $\delta^{30} \mathrm{Si}$ and $\delta^{29} \mathrm{Si}$ Determinations on USGS BHVO-1 and BHVO-2 Reference Materials with a New Configuration on a $\mathrm{Nu}$ Plasma Multi-Collector ICP-MS. Geostandards and Geoanalytical Research, 32(2), 193-202.

Albarède, F., Telouk, P., Blichert-Toft, J., Boyet, M., Agranier, A., \& Nelson, B. (2004). Precise and accurate isotopic measurements using multiple-collector ICPMS. Geochimica et Cosmochimica Acta, 68, 2725-2744.

Armytage, R. M. G., Georg, R. B., Williams, H. M., \& Halliday, A. N. (2012). Silicon isotopes in lunar rocks: Implications for the Moon's formation and the early history of the Earth. Geochimica et Cosmochimica Acta, 77, 504-514. http://doi.org/10.1016/j.gca.2011.10.032

Benjamini, Y., Hochberg, Y., 1995. Controlling the false discovery rate: a practical and powerful approach to multiple testing. Journal of the Royal Statisical Society 57 (1), 289-300. Boyd, P., LaRoche, J., Gall, M., Frew

Beucher, C. P., Brzezinski, M. A., \& Jones, J. L. (2008). Sources and biological fractionation of Silicon isotopes in the eastern Equatorial Pacific. Geochimica et Cosmochimica Acta, 72, 3063-3073.

Brzezinski, M. A., Jones, J. L. J., Beucher, C. P. C., Demarest, M. S. M., \& Berg, H. L. H. (2006). Automated determination of silicon isotope natural abundance by the acid decomposition of cesium hexafluosilicate. Analytical Chemistry, 78(17), 6109-6114.

Brzezinski, M. A., \& Jones, J. L. (2015). Coupling of the distribution of silicon isotopes to the meridional overturning circulation of the north Atlantic ocean. Deep Sea Research Part II: Topical Studies in Oceanography. 116, 79-88.

Brzezinski, M.A., Nelson, D.M., 1995. The annual silica cycle in the Sargasso Sea near Bermuda. Deep-Sea Reearch. I 42, 1215-1237.

Cao, Z., Frank, M., \& Dai, M. (2015). Dissolved silicon isotopic compositions in the East China Sea: Water mass mixing vs. biological fractionation. Limnology and Oceanography, 60(5), 1619-1633. 
Cardinal, D., Alleman, L. Y., De Jong, J., Ziegler, K., \& André, L. (2003). Isotopic composition of silicon measured by multicollector plasma source mass spectrometry in dry plasma mode. Journal of Analytical Atomic Spectrometry, 18, 213-218.

Cardinal D., Alleman, L.Y., Dehairs F., Svoye, N., Trull, T.W., Andre, L. (2005) Relevance of silicon isotopes to Si-nutrient utilization and Si-source assessment in Antarctic waters. Global Biogeochemical Cycles, 19, GB2007, doi:10.1029/2004GB002364

Closset I. (2015). The biogeochemical silicon cycle in the Southern Ocean tracked by isotopic approaches. Ph. D. thesis. Université Pierre \& Marie Curie, 222p.

De La Rocha, C., Brzezinski, M. A., \& DeNiro, M. J. (1996). Purification, Recovery, and LaserDriven Fluorination of Silicon from Dissolved and Particulate Silica for the Measurement of Natural Stable Isotope Abundances. Analytical Chemistry, 68, 3746-3750.

De La Rocha, C., Brzezinski, M. A., \& DeNiro, M. J. (2000). A first look at the distribution of stable isotopes of silicon in natural waters. Geochimica et Cosmochimica Acta, 64, 24672477.

De La Rocha, C. (2002). Measurement of silicon stable isotope natural abundances via multicollector inductively coupled plasma mass spectrometry (MC-ICP-MS). Geochemistry Geophysics Geosystems, 3(8), GC000310. http://doi.org/10.1029/ 2002 GC000310.

De La Rocha, C. L., Brzezinski, M.A., DeNiro, M.J. (2006). Opal-based isotopic proxies of paleoenvironmental conditions. Global Biogeochemical Cycles, 20, GB4S09, doi:10.1029/2005GB002664

De La Rocha, De, C. L., Bescont, P., Croguennoc, A., \& Ponzevera, E. (2011). The silicon isotopic composition of surface waters in the Atlantic and Indian sectors of the Southern Ocean. Geochimica et Cosmochimica Acta, 75(18), 5283-5295.

de Souza, G. F., Reynolds, B. C., Johnson, G. C., Bullister, J. L., \& Bourdon, B. (2012a). Silicon stable isotope composition traces Southern Ocean export of Si to the eastern South Pacific thermocline. Biogeosciences, 9, 4199-4213.

de Souza, G. F., Reynolds, B. C., Rickli, J., Frank, M., Saito, M. A, Gerringa, L. J. A., \& Bourdon, B. (2012b). Southern Ocean control of silicon stable isotope distribution in the deep Atlantic Ocean. Global Biogeochemical Cycles, 26, doi: 10.1029/2011GB004141 
de Souza, G. F., Slater, R. D., Dunne, J. P., \& Sarmiento, J. L. (2014). Deconvolving the controls on the deep ocean's silicon stable isotope distribution. Earth and Planetary Science Letters, 398, 66-76.

de Souza, G. F., Slater, R. D., Hain, M. P., Brzezinski, M. A., \& Sarmiento, J. L. (2015). Earth and Planetary Science Letters. Earth and Planetary Science Letters, 432, 342-353.

Ehlert, C., Grasse, P., Guitiérrez, D., Salvatteci, R., \& Frank, M. (2015). Nutrient utilisation and weathering inputs in the Peruvian upwelling region since the Little Ice Age. Climate of the Past, 11, 1-16.

Engstrom E., Rodushkin I., Baxter D.C., Ohlander, B. (2006) Chromatographic purification for the determination of dissolved silicon isotopic compositions in natural waters by high resolution multicollector inductively coupled plasma mass spectrometry. Analytical Chemistry, 75, 250-257.

Fietzke, J., \& Frische, M. (2015). Experimental evaluation of elemental behavior during LAICP-MS: influences of plasma conditions and limits of plasma robustness. Journal of Analytical Atomic Spectrometry, 31, 234-244.

Gao, S., Wolf Gladrow, D. A., \& Völker, C. (2016). Simulating the modern $\delta^{30}$ Si distribution in the oceans and in marine sediments. Global Biogeochemical Cycles, (GB005189). http://doi.org/10.1002/2015GB005189

Georg, R., Reynolds, B., Frank, M., \& Halliday, A. (2006). New sample preparation techniques for the determination of Si isotopic compositions using MC-ICPMS. Chemical Geology, 235(1-2), 95-104.

Grasse, P., Ehlert, C., \& Frank, M. (2013). The influence of water mass mixing on the dissolved $\mathrm{Si}$ isotope composition in the Eastern Equatorial Pacific. Earth and Planetary Science Letters, 380, 60-71.

Holzer, M., \& Brzezinski, M. A. (2015). Controls on the silicon isotope distribution in the ocean: New diagnostics from a data-constrained model. Global Biogeochemical Cycles, 29(3), 267-287.

Hughes, H. J., Delvigne, C., Korntheuer, M., de Jong, J., André, L., \& Cardinal, D. (2011). Controlling the mass bias introduced by anionic and organic matrices in silicon isotopic measurements by MC-ICP-MS. Journal of Analytical Atomic Spectrometry, 26(9), 18921896. 
Hulston J. R. and Thode H. G. (1965). Variations in the $\mathrm{S}^{33}, \mathrm{~S}^{34}$, and $\mathrm{S}^{36}$ contents of meteorites and their relation to chemical and nuclear effects. J. Geophys. Res. 70, 3475-3484.

Karl, \& Tien, G. (1992). MAGIC: A sensitive and precise method for measuring dissolves phosphorus in aquatic environments. Limnology and Oceanography, 37, 105-116.

Maier, E., Chapligin, B., Abelmann, A., Gersonde, R., Esper, O., Ren, J., et al. (2013). Combined oxygen and silicon isotope analysis of diatom silica from a deglacial subarctic Pacific record. Journal of Quaternary Science, 28(6), 571-581.

Nelson, D. M., Tréguer, P., Brzezinski, M. A., Leynaert, A. \& Quéguiner, B. 1995. Production and dissolution of biogenic silica in the ocean: Revised global estimates, comparison with regional data and relationship to biogenic sedimentation. Global Biogeochem. Cycles 9(3):359-72.

Reynolds, B., Frank, M., \& Halliday, A. (2006). Silicon isotope fractionation during nutrient utilization in the North Pacific. Earth and Planetary Science Letters, 244(1-2), 431-443.

Reynolds, B. C., Aggarwal, J., Andr, L., Baxter, D., Beucher, C., Brzezinski, M. A., et al. (2007). An inter-laboratory comparison of $\mathrm{Si}$ isotope reference materials. Journal of Analytical Atomic Spectrometry, 22(5), 561.

Reynolds, B. C., Frank, M., \& Halliday, A. N. (2008). Evidence for a major change in silicon cycling in the subarctic North Pacific at 2.73 Ma. Paleoceanography, 23(4), PA4219. http://doi.org/10.1029/2007PA001563

Rosman, K. J. R.; Taylor, P. D. P. (1998). Isotopic composition of the elements 1997. Pure Applied Chemistry, 70, 217-236.

Singh, S. P., Singh, S. K., Bhushan, R., \& Rai, V. K. (2015). Dissolved silicon and its isotopes in the water column of the Bay of Bengal: Internal cycling versus lateral transport. Geochimica et Cosmochimica Acta, 151, 172-191.

Sun, X., Olofsson, M., Andersson, P. S., Fry, B., Legrand, C., Humborg, C., Mörth, C.-M. 2014. Effects of growth and dissolution on the fractionation of silicon isotopes by estuarine diatoms. Geochimica et Cosmochimica Acta, 130,156-166.

Thiemens, M. H. (1999). Mass-Independent Isotope Effects in Planetary Atmospheres and the Early Solar System. Science, 283 (5400), 341-345. 
Tréguer, P. J., \& La Rocha, De, C. L. (2013). The World Ocean Silica Cycle. Annual Review of Marine Science, 5(1), 477-501.

van den Boorn, S. H. J. M., Vroon, P. Z., \& van Bergen, M. J. (2009). Sulfur-induced offsets in MC-ICP-MS silicon-isotope measurements. Journal of Analytical Atomic Spectrometry 24, doi: 10.1039/b816804k.

Verhoeven, K.J.F., Simonsen, K.L., McIntyre, L.M., 2005. Implementing false discovery rate control: increasing your power. Oikos 108, 643-647.

Young, E. D., Galy, A., \& Nagahara, H. (2002). Kinetic and equilibrium mass-dependent isotope fractionation laws in nature and their geochemical and cosmochemical significance. Geochimica Et Cosmochimica Acta, 66(6), 1095-1104.

Zhang, A., Zhang, J., Zhang, R., \& Xue, Y. (2014). Modified enrichment and purification protocol for dissolved silicon isotope determination in natural waters. Journal of Analytical Atomic Spectrometry. doi:10.1039/C4JA00122B

Zhang, A., Zhang, J., Hu, J., Zhang, R., \& Zhang, G. (2015a) Silicon isotopic chemistry in the Changjiang Estuary and coastal regions: Impacts of physical and biogeochemical processes on the transport of riverine dissolved silica. Journal of Geophysical Research: Oceans, 10.1002/2015JC011050

Zhang, A., Zhang, J., Zhang, R., \& Xue, Y. (2015b). Determination of stable silicon isotopes using multi-collector inductively coupled plasma mass spectrometry. Chinese Journal of Analytical Chemistry, 43(9): 1353-1359. 
Figure Captions:

Figure 1. $\delta^{30} \mathrm{Si}(\mathrm{OH})_{4}$ results from all groups for $\mathrm{ALOHA}_{300}$ (open circles) and $\mathrm{ALOHA}_{1000}$ (filled circles). The long black vertical solid line indicates the mean value of all measurements for $\mathrm{ALOHA}_{1000}$ and the long dashed line that for $\mathrm{ALOHA}_{300}$. The data points represent the individual $\delta^{30} \mathrm{Si}(\mathrm{OH})_{4}$ values from Table A2. Short vertical solid lines are the means obtained by individual laboratories for the two samples. Uncertainty in the mean for all measurements for each sample $(2 \mathrm{~s}$. d. $)$ is indicated by the horizontal bars at the top of the figure.

Figure 2. $\mathrm{Z}$ scores as a function of $\delta^{30} \mathrm{Si}(\mathrm{OH})_{4}$ for $\mathrm{ALOHA}_{300}$ (open circles) and $\mathrm{ALOHA}_{1000}$ (filled circles).

Figure 3. Plot of $\delta^{30} \mathrm{Si}(\mathrm{OH})_{4}$ versus $\delta^{29} \mathrm{Si}(\mathrm{OH})_{4}$ for $\mathrm{ALOHA}_{300}$ (open circle) and $\mathrm{ALOHA}_{1000}$ (filled circle; error bars are 2 s. d.). Solid line is the result of least-squares linear regression with a slope of $0.5188 \pm$ 0.0184 (s.e., $\mathrm{R}^{2}=0.98$ ). The lower and upper $95 \%$ confidence intervals are given as dashed black lines. The kinetic fractionation line has a slope of 0.5092 (intercept of zero) for Si (dashed red line) and the equilibrium fractionation line has a slope of 0.5178 (intercept of zero) for Si (solid red line). Regression line obtained by analysis using reduced major axis model II regression yields a slope of $0.5131 \pm 0.0040$ (s.e., $\mathrm{R}^{2}=0.98$; not displayed in the figure).

Figure 4. Boxplots showing $\delta^{30} \mathrm{Si}(\mathrm{OH})_{4}$ data sorted by different mass spectrometer types for a) $\mathrm{ALOHA}_{300}$ and for b) $\mathrm{ALOHA}_{1000}$. Data sorted by different precipitation methods for c) $\mathrm{ALOHA}_{300}$ and d) $\mathrm{ALOHA}_{1000}$. On the boxplots the median values (black) and the mean values (grey) are displayed. For $\mathrm{ALOHA}_{300}$ a) and c) show data for IRMS and TEA-Moly with (grey boxplot) and without outlier (black boxplot). Here, the mean value (which equals the median) is indicated by a superscript star. The value next to each boxplot indicates the median (black) and the mean (grey), respectively. The number of included data points (n) is given below each boxplot. Raw data are presented in Table 3 
Table 1: Summary of the different participating laboratory groups and methods for sample preparation and mass spectrometry.

\begin{tabular}{|c|c|c|c|c|c|c|c|c|c|}
\hline No. & Lab & Country & $\begin{array}{l}\text { Resposible } \\
\text { person }\end{array}$ & $\begin{array}{c}\text { Sample } \\
\text { Introduction }\end{array}$ & $\begin{array}{c}\text { Mass } \\
\text { spectrometry }\end{array}$ & $\begin{array}{l}\text { Precipitation } \\
\quad \text { Method }\end{array}$ & Further preparation & Extras & References \\
\hline 1 & MPI Oldenburg & Germany & $\begin{array}{l}\text { Claudia Ehlert, } \\
\text { Katharina } \\
\text { Pahnke }\end{array}$ & Wet-plasma & Neptune Plus & $\mathrm{NaOH}$ & $\begin{array}{c}\text { Cation Exchange Resin } \\
\text { (AG50W-X8) }\end{array}$ & $\begin{array}{c}\mathrm{H}_{2} \mathrm{O}_{2} / \mathrm{UV} \\
\text { treatment } / \mathrm{Mg} \\
\text { doping }\end{array}$ & $\begin{array}{l}\text { Georg et al. 2006; } \\
\text { Hughes et al. } 2011\end{array}$ \\
\hline 2 & LOCEAN/LSCE & France & $\begin{array}{c}\text { Damien } \\
\text { Cardinal, Ivia } \\
\text { Closset, }\end{array}$ & $\begin{array}{l}\text { Apex, } \\
\text { Dry-plasma }\end{array}$ & Neptune Plus & $\mathrm{NaOH}$ & $\begin{array}{c}\text { Cation Exchange Resin } \\
\text { (AG50W-X8) }\end{array}$ & $\begin{array}{c}\mathrm{Mg} / / \mathrm{SO}_{4}{ }^{2-} \\
\text { Doping }\end{array}$ & $\begin{array}{c}\text { Karl and Tien 1992; } \\
\text { Georg et al. 2006; } \\
\text { Hughes et al. 2011 }\end{array}$ \\
\hline 3 & $\begin{array}{l}\text { Unité de Recherche } \\
\text { Géosciences Marines, } \\
\text { IFREMER and } \\
\text { Université de Brest }\end{array}$ & France & Jill Sutton & $\begin{array}{c}\text { Apex, } \\
\text { Dry- plasma }\end{array}$ & Neptune & TEA-Moly & $\begin{array}{c}\text { Anion Exchange Resin } \\
\text { (AG1-X8) }\end{array}$ & Mg doping & $\begin{array}{l}\text { Cardinal et al. 2005; } \\
\text { Engström et al. } \\
\text { 2006; De La Rocha } \\
\text { et al. 2006; De } \\
\text { LaRoch et al. } 2011\end{array}$ \\
\hline 4 & ETH Zürich & Switzerland & $\begin{array}{l}\text { Florian Wetzel, } \\
\text { Gregory de } \\
\text { Souza }\end{array}$ & $\begin{array}{l}\text { DSN-100, Dry- } \\
\text { plasma }\end{array}$ & Nu Plasma 1700 & $\mathrm{NaOH}$ & $\begin{array}{c}\text { Cation Exchange Resin } \\
\text { (AG50W-X8) }\end{array}$ & & $\begin{array}{l}\text { Georg et al. 2006; } \\
\text { deSouza et al. } 2012\end{array}$ \\
\hline 5 & $\begin{array}{l}\text { Swedish Museum of } \\
\text { Natural History }\end{array}$ & Sweden & $\begin{array}{l}\text { Per Andersson, } \\
\text { Xiaole Sun }\end{array}$ & Wet-plasma & Nu Plasma II & $\mathrm{NaOH}$ & $\begin{array}{c}\text { Cation Exchange Resin } \\
\text { (AG50W-X8) }\end{array}$ & & $\begin{array}{l}\text { Georg et al. 2006; } \\
\text { Sun et al. } 2014\end{array}$ \\
\hline 6 & $\begin{array}{l}\text { GEOMAR Helmholz } \\
\text { Institute for Ocean } \\
\text { Research }\end{array}$ & Germany & $\begin{array}{l}\text { Patricia Grasse, } \\
\text { Martin Frank }\end{array}$ & $\begin{array}{l}\text { Aridus II, Dry- } \\
\text { plasma }\end{array}$ & Nu Plasma II & $\mathrm{NaOH} / \mathrm{NH}_{4}$ & $\begin{array}{c}\text { Cation Exchange Resin } \\
\text { (AG50W-X8) }\end{array}$ & & $\begin{array}{c}\text { Karl and Tien 1992; } \\
\text { Georg et al. 2006; } \\
\text { Zhang et al. 2014 }\end{array}$ \\
\hline 7 & $\begin{array}{l}\text { University of British } \\
\text { Columbia }\end{array}$ & Canada & Nicolas Estrade & $\begin{array}{l}\text { Aridus II, } \\
\text { Dry-plasma }\end{array}$ & Nu Plasma 1700 & $\mathrm{NH}_{4}$ & $\begin{array}{c}\text { Cation Exchange Resin } \\
\text { (AG50W-X8) }\end{array}$ & & $\begin{array}{l}\text { Karl and Tien 1992; } \\
\text { Zhang et al. } 2014\end{array}$ \\
\hline 8 & $\begin{array}{c}\text { University of } \\
\text { California Santa } \\
\text { Barbara }\end{array}$ & US & $\begin{array}{c}\text { Janice Jones, } \\
\text { Patricia Grasse, } \\
\text { Mark } \\
\text { Brzezinski }\end{array}$ & $\begin{array}{l}\text { Dual-inlet } \\
\text { gas-source }\end{array}$ & $\begin{array}{l}\text { Kiel III MAT } \\
252\end{array}$ & TEA-Moly & $\begin{array}{l}\text { HF dissolution, then } \\
\mathrm{CsSiF}_{6} \text { precipitation }\end{array}$ & & $\begin{array}{l}\text { De LaRocha et al. } \\
\text { 1996; Brzezinski et } \\
\text { al. } 2006\end{array}$ \\
\hline 9 & Xiamen University & China & $\begin{array}{l}\text { Minhan Dai, } \\
\text { Zhouling Zang }\end{array}$ & Dry-plasma & $\mathrm{Nu}$ Plasma II & $\mathrm{NaOH}$ & $\begin{array}{c}\text { Cation Exchange Resin } \\
\text { (AG50W-X8) }\end{array}$ & & $\begin{array}{l}\text { Karl and Tien 1992; } \\
\text { Georg et al. } 2006\end{array}$ \\
\hline 10 & $\begin{array}{l}\text { Research Center for } \\
\text { Eco-Environmental } \\
\text { Sciences,CAS Beijing }\end{array}$ & China & Qian Liu & $\begin{array}{l}\text { DSN-100, Dry- } \\
\text { plasma }\end{array}$ & $\mathrm{Nu}$ Plasma II & $\mathrm{NaOH}$ & $\begin{array}{l}\text { Cation Exchange Resin } \\
\text { (Dowex50W-X8) }\end{array}$ & & $\begin{array}{l}\text { Karl and Tien 1992; } \\
\text { Georg et al. } 2006\end{array}$ \\
\hline 11 & $\begin{array}{c}\text { State Key Laboratory } \\
\text { of Estuarine and } \\
\text { Coastal Research, } \\
\text { Shanghai }\end{array}$ & China & Anyu Zhang & Dry-plasma & Neptune & $\mathrm{NH}_{4}$ & $\begin{array}{l}\text { Cation Exchange Resin } \\
\text { (Dowex50W-X8) }\end{array}$ & & $\begin{array}{l}\text { Georg et al. 2006; } \\
\text { Zhang et al. 2014; } \\
\text { Zhang et al. } 2015\end{array}$ \\
\hline
\end{tabular}


Table 2: Summary of mean $\mathrm{Si}$ isotope values $\left(\delta^{30} \mathrm{Si}, \delta^{29} \mathrm{Si}\right)$, the associated $2 \sigma$ analytical uncertainty $(2$ s.d. $)$, number of chemical preparations $(\mathrm{N})$ and the number of measurements (n) obtained by each laboratory group for $\mathrm{ALOHA}_{300}$ and $\mathrm{ALOHA}_{1000}$. Overall mean, uncertainty about the mean (2 s.d.), median as well as the interquartile deviation (IQD) for all groups are given at the bottom of the table. NaN indicates data not available (for a compilation of all measurements see Table A2).

\begin{tabular}{|c|c|c|c|c|c|c|c|c|c|c|c|c|c|c|}
\hline \multirow[b]{2}{*}{ Group No. } & \multicolumn{7}{|c|}{ Aloha $_{300}$} & \multicolumn{7}{|c|}{ Aloha $_{1000}$} \\
\hline & $\delta^{30} \mathrm{Si}$ & 2 s.d. & $\delta^{29} \mathrm{Si}$ & 2 s.d. & $\delta^{29} \mathrm{Si} / \delta^{30} \mathrm{Si}$ & $\mathbf{N}$ & $\mathbf{n}$ & $\delta^{30} \mathbf{S i}$ & 2 s.d. & $\delta^{29} \mathrm{Si}$ & 2 s.d. & $\delta^{29} \mathrm{Si} / \delta^{30} \mathrm{Si}$ & $\mathbf{N}$ & $\mathbf{n}$ \\
\hline 1 & $\mathrm{NaN}$ & $\mathrm{NaN}$ & $\mathrm{NaN}$ & $\mathrm{NaN}$ & $\mathrm{NaN}$ & $\mathrm{NaN}$ & $\mathrm{NaN}$ & 1.10 & 0.07 & 0.63 & 0.07 & 0.57 & 4 & 4 \\
\hline 2 & 1.66 & 0.10 & 0.84 & 0.05 & 0.50 & 6 & 12 & 1.10 & 0.07 & 0.56 & 0.02 & 0.51 & 5 & 15 \\
\hline 3 & $\mathrm{NaN}$ & $\mathrm{NaN}$ & $\mathrm{NaN}$ & $\mathrm{NaN}$ & $\mathrm{NaN}$ & $\mathrm{NaN}$ & $\mathrm{NaN}$ & 1.16 & 0.16 & 0.59 & 0.09 & 0.51 & 3 & 9 \\
\hline 4 & 1.64 & 0.13 & 0.87 & 0.05 & 0.53 & 4 & 12 & 1.17 & 0.20 & 0.62 & 0.10 & 0.53 & 3 & 12 \\
\hline 5 & 1.51 & 0.12 & 0.80 & 0.08 & 0.53 & 3 & 11 & 1.23 & 0.08 & 0.64 & 0.04 & 0.52 & 4 & 15 \\
\hline 6 & 1.78 & 0.18 & 0.89 & 0.18 & 0.50 & 6 & 6 & 1.26 & 0.12 & 0.68 & 0.09 & 0.54 & 5 & 5 \\
\hline 7 & 1.92 & 0.08 & 1.02 & 0.12 & 0.53 & 5 & 14 & 1.25 & 0.07 & 0.65 & 0.07 & 0.52 & 6 & 31 \\
\hline 8 & 1.46 & 0.17 & 0.75 & 0.09 & 0.51 & 3 & 10 & 1.29 & 0.04 & 0.66 & 0.02 & 0.51 & 4 & 25 \\
\hline 9 & 1.94 & 0.12 & 0.99 & 0.08 & 0.51 & 8 & 16 & 1.31 & 0.15 & 0.68 & 0.09 & 0.52 & 10 & 20 \\
\hline 10 & 1.53 & 0.17 & 0.79 & 0.11 & 0.52 & 3 & 9 & 1.45 & 0.17 & 0.76 & 0.16 & 0.53 & 3 & 9 \\
\hline 11 & 1.69 & 0.24 & 0.85 & 0.17 & 0.50 & 8 & 8 & 1.27 & 0.05 & 0.65 & 0.03 & 0.51 & 8 & 72 \\
\hline Mean & 1.68 & & 0.87 & & 0.52 & & & 1.24 & & 0.65 & & 0.52 & & \\
\hline 2 s.d. & 0.35 & & 0.10 & & & & & 0.20 & & 0.10 & & & & \\
\hline Median & 1.66 & & 0.85 & & & & & 1.25 & & 0.65 & & & & \\
\hline Modal Value & 1.66 & & 0.85 & & & & & 1.22 & & 0.65 & & & & \\
\hline IQD & 0.13 & & 0.05 & & & & & 0.05 & & 0.02 & & & & \\
\hline
\end{tabular}


Table 3: Statistics for $\delta^{30} \mathrm{Si}(\mathrm{OH})_{4}$ values sorted by different instrument types and precipitation methods (for details see Appendix 2). NaN denotes sample not available.

\begin{tabular}{|c|c|c|c|c|c|c|}
\hline \multicolumn{7}{|c|}{ Grouped by Instrument } \\
\hline & \multicolumn{3}{|c|}{ Aloha $_{300}$} & \multicolumn{3}{|c|}{ Aloha $_{1000}$} \\
\hline & Neptune & $\mathrm{Nu}$ & IRMS & Neptune & $\mathrm{Nu}$ & IRMS \\
\hline Median & 1.64 & 1.81 & 1.51 & 1.15 & 1.28 & 1.28 \\
\hline Mean & 1.68 & 1.78 & 1.46 & 1.18 & 1.28 & 1.29 \\
\hline 2 s.d. & 0.19 & 0.36 & 0.17 & 0.18 & 0.18 & 0.04 \\
\hline Min & 1.52 & 1.45 & 1.36 & 1.07 & 1.08 & 1.27 \\
\hline Max & 1.86 & 2.05 & 1.52 & 1.30 & 1.55 & 1.31 \\
\hline $\mathbf{N}$ & 14 & 29 & 3 & 20 & 31 & 4 \\
\hline
\end{tabular}

Grouped by Precipitation

\begin{tabular}{cccc|ccc}
\hline & \multicolumn{3}{c}{$\begin{array}{c}\text { Aloha } \\
\end{array}$} & MAGIC & $\begin{array}{c}\text { Aloha } \\
\text { Ammonia }\end{array}$ & \multicolumn{2}{c}{ TEA-Moly } & MAGIC & Ammonia & TEA-Moly \\
\hline Median & 1.69 & 1.82 & 1.51 & 1.25 & 1.27 & 1.27 \\
Mean & 1.73 & 1.78 & 1.46 & 1.24 & 1.26 & 1.23 \\
2 s.d. & 0.34 & 0.30 & 0.17 & 1.25 & 0.06 & 0.16 \\
Min & 1.45 & 1.52 & 1.36 & 1.07 & 1.20 & 1.10 \\
Max & 2.05 & 1.97 & 1.52 & 1.55 & 1.30 & 1.31 \\
N & 30 & 13 & 3 & 32 & 16 & 7
\end{tabular}


Table A1: Detailed Overview of chemical preparation and measurement methods $(1 / 5 ; \mathrm{Nu}$ Plasma)

\begin{tabular}{|c|c|c|c|c|c|c|}
\hline Group & 4 & 5 & 6 & 7 & 9 & 10 \\
\hline Sample Vol. $\left(\right.$ Aloha $\left._{300}\right)$ & $50 \mathrm{ml}$ & $50 \mathrm{ml}$ & $30 \mathrm{ml}$ & $12 \mathrm{ml}$ & $15 \mathrm{ml}$ & $15 \mathrm{ml}$ \\
\hline Sample Vol. (Aloha $\left.{ }_{1000}\right)$ & $10 \mathrm{ml}$ & $10 \mathrm{ml}$ & $10 \mathrm{ml}$ & $12 \mathrm{ml}$ & $10 \mathrm{ml}$ & $10 \mathrm{ml}$ \\
\hline \multirow[t]{2}{*}{ Precipitation Method } & MAGIC & MAGIC & MAGIC & MAGIC & MAGIC & MAGIC \\
\hline & $\begin{array}{l}\text { Sodium } \\
\text { hydroxide }\end{array}$ & $\begin{array}{l}\text { Ammonium } \\
\text { Hydroxid }\end{array}$ & $\begin{array}{c}\text { Ammonium \& } \\
\text { Sodium Hydroxid }\end{array}$ & $\begin{array}{l}\text { Ammonium } \\
\text { Hydroxid }\end{array}$ & $\begin{array}{l}\text { Sodium } \\
\text { Hydroxid }\end{array}$ & $\begin{array}{l}\text { Ammonium } \\
\text { Hydroxid }\end{array}$ \\
\hline \multirow[t]{2}{*}{ Column Chemistry } & $\begin{array}{c}\text { Cation } \\
\text { Exchange } \\
\text { Resin }\end{array}$ & $\begin{array}{c}\text { Cation Exchange } \\
\text { Resin }\end{array}$ & $\begin{array}{c}\text { Cation Exchange } \\
\text { Resin }\end{array}$ & $\begin{array}{c}\text { Cation Exchange } \\
\text { Resin }\end{array}$ & $\begin{array}{c}\text { Cation } \\
\text { Exchange Resin }\end{array}$ & $\begin{array}{c}\text { Cation Exchange } \\
\text { Resin }\end{array}$ \\
\hline & $\begin{array}{l}\text { AG50W-X8, } \\
200-400 \text { mesh }\end{array}$ & AG50W-X12 & $\begin{array}{l}\text { AG50W-X8, 200- } \\
400 \text { mesh }\end{array}$ & $\begin{array}{l}\text { AG50W-X8, 200- } \\
400 \text { mesh }\end{array}$ & $\begin{array}{l}\text { AG50W-X8, } \\
200-400 \text { mesh }\end{array}$ & Dowex50W-X8 \\
\hline $\begin{array}{l}\text { Amount } \mathrm{Si}(\mu \mathrm{g}) \text { introduced } \\
\text { into machine }\end{array}$ & $2.5 \mu \mathrm{g}$ & 0.6 to $1.6 \mu \mathrm{g}$ & $2.5 \mu \mathrm{g}$ & $1.4 \mu \mathrm{g}$ & & $1.8 \mu \mathrm{g}$ \\
\hline Mg Doping (yes/no) & no & no & no & no & no & yes \\
\hline Extras & & $\begin{array}{l}\text { Aloha }_{300} \text { evaporated } \\
\text { after column to } \\
\text { double concentration }\end{array}$ & $\begin{array}{c}\text { Aloha }_{300} \text { evaporated } \\
\text { after column to } \\
\text { double } \\
\text { concentration } \\
\end{array}$ & & & \\
\hline $\begin{array}{l}\text { Co-precipiation for } \\
\text { Aloha }_{1000} \text { and Aloha } \\
\end{array}$ & $2.5 \mu \mathrm{g}$ & 0.6 to $1.6 \mu \mathrm{g}$ & $2.5 \mu \mathrm{g}$ & $1.4 \mu \mathrm{g}$ & & $1.8 \mu \mathrm{g}$ \\
\hline
\end{tabular}


Table A1: Detailed Overview of chemical preparation and measurement methods $(2 / 5 ; \mathrm{Nu}$ Plasma)

\begin{tabular}{|c|c|c|c|c|c|c|}
\hline Group & 4 & 5 & 6 & 7 & 9 & 10 \\
\hline Mass spectrometer & $\begin{array}{l}\text { Nu plasma (1700) } \\
\text { HR-MC-ICP-MS }\end{array}$ & $\begin{array}{l}\text { Nu plasma (II) } \\
\text { MC-ICP-MS }\end{array}$ & $\begin{array}{l}\text { Nu plasma (II) MC- } \\
\text { ICP-MS }\end{array}$ & $\begin{array}{l}\text { Nu plasma (1700) } \\
\text { HR-MC-ICP-MS }\end{array}$ & $\begin{array}{l}\text { Nu plasma (II) } \\
\text { MC-ICP-MS }\end{array}$ & $\begin{array}{c}\text { Nu plasma (II) MC- } \\
\text { ICP-MS } \\
\end{array}$ \\
\hline Sample introduction & $\begin{array}{l}\text { Desolvator DSN- } \\
100 ; \\
\text { PFA nebulizer; } \\
\sim 75 \mu \mathrm{L} / \mathrm{min} \\
\text { uptake rate }\end{array}$ & $\begin{array}{l}\text { wet plasma } \\
\text { glass nebulizer } \\
\sim 100 \mu \mathrm{L} / \mathrm{min} \\
\text { uptake rate }\end{array}$ & $\begin{array}{l}\text { Desolvator Cetac } \\
\text { Aridus II } \\
\text { PFA nebulizer } \\
\sim 70 \mu \mathrm{L} / \text { min uptake } \\
\text { rate }\end{array}$ & $\begin{array}{l}\text { Desolvator Cetac } \\
\text { Aridus II } \\
\text { PFA nebulizer, } \\
\sim 100 \mu \mathrm{L} / \mathrm{min} \\
\text { uptake rate }\end{array}$ & $\begin{array}{l}\text { Desolvation } \\
\text { Nebulizer } \\
\text { System } \\
\text { PFA nebulizer } \\
\sim 80 \mu \mathrm{L} / \mathrm{min} \\
\text { uptake rate }\end{array}$ & $\begin{array}{c}\text { DeSolvation } \\
\text { Nebulizer (DSN-100) } \\
\text { PFA nebulizer } \\
\sim 70 \mu \mathrm{L} / \text { min uptake } \\
\text { rate }\end{array}$ \\
\hline Cones & common Ni cones & common Ni cones & common Ni cones & common Ni cones & $\begin{array}{c}\text { common } \mathrm{Ni} \\
\text { cones }\end{array}$ & common Ni cones \\
\hline \multirow[t]{2}{*}{ Torch } & $\begin{array}{l}\text { semi-demountable } \\
\text { quartz torch }\end{array}$ & glass & glass & glass & glass & glass \\
\hline & alumina injector & & & & & \\
\hline Measurement mode & high resolution & $\begin{array}{c}\text { medium } \\
\text { resolution; } \mathrm{m} / \Delta \mathrm{m} \\
4000-7000\end{array}$ & medium resolution & high resolution & $\begin{array}{l}\text { medium } \\
\text { resolution }\end{array}$ & medium resolution \\
\hline \multirow[t]{3}{*}{$\begin{array}{l}\text { Standard-Sample- } \\
\text { Bracketing }\end{array}$} & yes & yes & yes & yes & yes & yes \\
\hline & $\begin{array}{c}\text { smp. repeated } 5 \\
\text { times } \\
\end{array}$ & $\begin{array}{c}\text { smp. repeated } 3 \\
\text { times }\end{array}$ & $\begin{array}{c}\text { smp. repeated } 4-5 \\
\text { times } \\
\end{array}$ & $\begin{array}{c}\text { smp. repeated } 3 \\
\text { times }\end{array}$ & $\begin{array}{l}\text { smp. repeated } \\
4 \sim 5 \text { times }\end{array}$ & smp. repeated 3 times \\
\hline & $\begin{array}{l}1 \text { block, } 36 \text { cycles } \\
\text { of } 5 \mathrm{sec} \text { each }\end{array}$ & $\begin{array}{c}2 \text { blocks, } 20 \\
\text { cycles }\end{array}$ & 1 block, 60 cycles & $\begin{array}{c}1 \text { block, } 25 \text { cycles }, \\
10 \mathrm{sec}\end{array}$ & $\begin{array}{c}1 \text { block, } 20 \\
\text { cycles }\end{array}$ & 4 block, 15 cycles \\
\hline $\begin{array}{l}\text { Measurement intensity } \\
\left({ }^{28} \mathrm{Si}\right)\end{array}$ & $6-7 \mathrm{~V}$ & $2-3.5 \mathrm{~V} / \mathrm{ppm}$ & $4 \mathrm{~V}$ & $\begin{array}{l}9 \mathrm{~V} \text { for } 0.35 \mathrm{ppm} \\
\mathrm{Si}\end{array}$ & $6 \mathrm{~V}$ & $5.5 \mathrm{~V} / \mathrm{ppm}$ \\
\hline Blanks $\left({ }^{28} \mathrm{Si}\right)$ & 10 to $30 \mathrm{mV}$ & $10-30 \mathrm{mV}$ & 10 to $30 \mathrm{mV}$ & $\begin{array}{c}40-100 \mathrm{mV}, \\
\text { measured by OPZ }\end{array}$ & 50 to $80 \mathrm{mV}$ & 16 to $36 \mathrm{mV}$ \\
\hline
\end{tabular}


Table A1: Detailed Overview of chemical preparation and measurement methods (3/5; Neptune)

\begin{tabular}{|c|c|c|c|c|}
\hline Group & 1 & 2 & 3 & 11 \\
\hline Sample Vol. $\left(\right.$ Aloha $\left._{300}\right)$ & - & $50 \mathrm{ml}$ & - & $8 \mathrm{ml}$ \\
\hline Sample Vol. $\left(\right.$ Aloha $\left._{1000}\right)$ & $10 \mathrm{ml}$ & $10 \mathrm{ml}$ & $100 \mathrm{~mL}$ & $1 \mathrm{ml}$ \\
\hline \multirow[t]{2}{*}{ Precipitation Method } & MAGIC & MAGIC & Triethylamine silicomolybdate & MAGIC \\
\hline & Sodium Hydroxide & Sodium Hydroxide & Sodium Hydroxide & Ammonium Hydroxid \\
\hline \multirow[t]{2}{*}{ Column Chemistry } & Cation Exchange Resin & Cation Exchange Resin & Anion Exchange Resin & $\begin{array}{c}\text { Cation Exchange } \\
\text { Resin (Dowex 50W- } \\
\text { X8) } \\
\end{array}$ \\
\hline & (AG50W-X12, 200-400 mesh) & (AG50W-X12, 200-400 mesh) & (AG1-X8) & \\
\hline $\begin{array}{l}\text { Amount } \mathrm{Si}(\mu \mathrm{g}) \\
\text { introduced in the } \\
\text { machine }\end{array}$ & $0.6 \mathrm{ppm}$ & $7 \mu \mathrm{g}$ & $1.2 \mu \mathrm{g}$ & $2.5 \mu \mathrm{g}$ \\
\hline Mg Doping (yes/no) & yes & yes & Yes & no \\
\hline Extras & treatment with $\mathrm{H}_{2} \mathrm{O}_{2} / \mathrm{UV}$ light & $\begin{array}{c}\text { sulfate doping; } \\
\text { anion concentration checked; } \\
\text { Aloha } 300 \text { evaporated after column } \\
\text { to double concentration }\end{array}$ & $\begin{array}{l}\text { Combustion of precipitate in } \\
\text { platinum crucibles Dissolution of } \\
\text { purified } \mathrm{SiO}_{2} \text { in } \mathrm{HF}\end{array}$ & no \\
\hline $\begin{array}{l}\text { Co-precipitation for } \\
\text { Aloha }_{1000} \text { and Aloha } \\
300\end{array}$ & yes/yes & yes/yes & yes/yes & yes/yes \\
\hline
\end{tabular}


Table A1: Detailed Overview of chemical preparation and measurement methods $(4 / 5$; Neptune)

\begin{tabular}{|c|c|c|c|c|}
\hline Group & 1 & 2 & 3 & 11 \\
\hline \multirow[t]{2}{*}{ Mass spec } & Neptune Plus MC-ICP-MS & Neptune Plus MC-ICP-MS & $\begin{array}{l}\text { Thermo Scientific Neptune MC- } \\
\text { ICP-MS }\end{array}$ & Neptune MC-ICP-MS \\
\hline & (Thermo-Fisher, Germany) & (Thermo-Fisher, Germany) & & \\
\hline Sample introduction & $\begin{array}{c}\text { Wet Plasma; } \\
\text { Quartz spray chamber; } \\
\text { PFA nebulizer; } \\
\sim 70 \mu \mathrm{L} / \text { min uptake rate }\end{array}$ & $\begin{array}{l}\text { Desolvator APEX (ESI); } \\
\text { PFA nebulizer; } \\
100 \mu \mathrm{L} / \text { min uptake rate }\end{array}$ & $\begin{array}{c}\text { Desolvator Apex (ESI); } \\
\text { PFA nebulizer; } \\
100 \mu \mathrm{L} / \text { min uptake rate }\end{array}$ & $\begin{array}{l}\text { Apex-IR; } \\
\text { PFA nebulizer; } \\
\sim 100 \mu \mathrm{L} / \mathrm{min} ; \\
\text { uptake rate }\end{array}$ \\
\hline \multirow[t]{2}{*}{ Cones } & $\begin{array}{l}\text { H-skimmer, Jet-sampler (Ni } \\
\text { cones) }\end{array}$ & Nickel X-Skimmer cone & common $\mathrm{Ni}$ cones & Standard sampling cone \\
\hline & & Standard Ni-Sample cone & & $\mathrm{X}$ skimmer cone \\
\hline Torch & glass & Quartz + alumina injector & glass & glass \\
\hline \multirow[t]{4}{*}{ Measurement mode } & medium resolution & medium resolution & medium resolution & medium resolution \\
\hline & standard-sample bracketing & standard-sample bracketing & standard-sample bracketing & $\begin{array}{l}\text { standard-sample } \\
\text { bracketing }\end{array}$ \\
\hline & smp repeated 3 times & smp repeated 2-3 times & $>3$ replicates & smp repeated 3 times \\
\hline & 1 block, 30 cycles & 3 blocks, 20 cycles per block & 1 block, 25 cycles & $\begin{array}{l}1 \text { block, } 30 \text { cycles, } 8 \mathrm{~s} \\
\text { integration time }\end{array}$ \\
\hline $\begin{array}{l}\text { Measurement intensity } \\
\left({ }^{28} \mathrm{Si}\right)\end{array}$ & $8 \mathrm{~V}$ & $6 \mathrm{~V}$ & $12 \mathrm{~V}$ & 2.5 to $3 \mathrm{~V}$ \\
\hline Blanks $\left({ }^{28} \mathrm{Si}\right)$ & 20 to $30 \mathrm{mV}$ & 10 to $50 \mathrm{mV}$ & 10 to $30 \mathrm{mV}$ & 10 to $20 \mathrm{mV}$ \\
\hline
\end{tabular}


Table A1: Detailed Overview of chemical preparation and measurement methods (5/5; IRMS)

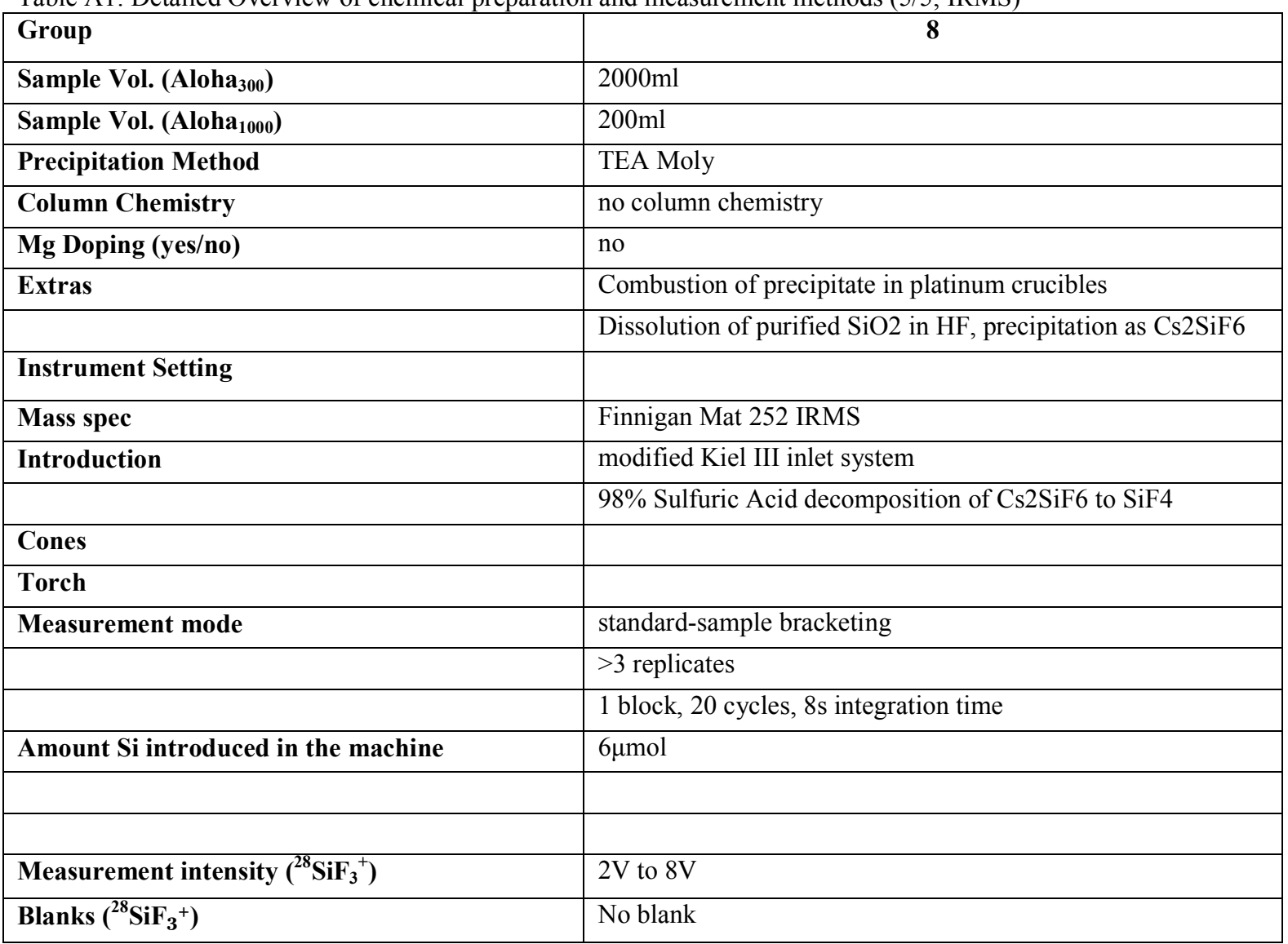


Table A2: Measurements of $\delta^{30} \mathrm{Si}(\mathrm{OH})_{4}$ and ${ }^{29} \mathrm{Si}(\mathrm{OH})_{4}$ by each laboratory group for ALOHA 1000 . The means of analytical replicates, $\delta^{30} \mathrm{Si}$ and $\delta^{29} \mathrm{Si}$, and associated 2 sigma standard deviations where analytical replicates are defined as replicate analyses from the same chemical preparation. Averages across chemical preparations within a laboratory group are given by ${ }^{30} \mathrm{Si}$-mean and $\delta^{29} \mathrm{Si}$ mean with associated 2 sigma standard deviations, 2sd_mean. $\mathrm{N}$ and $\mathrm{n}$ denote the total number of chemical preparations and analytical replicates for each laboratory group, respectively. NaN indicates data not available.

\begin{tabular}{|c|c|c|c|c|c|c|c|c|c|c|c|c|}
\hline \multirow{2}{*}{$\begin{array}{l}\text { Group } \\
\text { Aloha } \\
\text { 1000m } \\
\end{array}$} & $\delta^{30} \mathbf{S i}$ & $\begin{array}{c}2 \\
\text { s.d. }\end{array}$ & $\delta^{29} \mathrm{Si}$ & $\begin{array}{c}2 \\
\text { s.d. }\end{array}$ & ${ }^{29 / 30} \mathrm{Si}$ & $\mathbf{n}$ & $\begin{array}{c}\delta^{30} \mathrm{Si} \\
\text { mean }\end{array}$ & $\begin{array}{l}2 \text { s.d. } \\
\text { mean }\end{array}$ & $\begin{array}{c}\delta^{29} \mathrm{Si} \\
\text { mean }\end{array}$ & $\begin{array}{l}2 \text { s.d. } \\
\text { mean }\end{array}$ & $\mathbf{N}$ & n \\
\hline & {$[\% 0]$} & [\%o] & [\%o] & [\%o] & [\%o] & $\begin{array}{l}\text { analyt. } \\
\text { replicate }\end{array}$ & [\%o] & [\%o] & [\%o] & [\%o] & & \\
\hline \multirow[t]{4}{*}{1} & 1.15 & 0.02 & 0.68 & 0.07 & 0.59 & 1 & 1.10 & 0.07 & 0.63 & 0.07 & 4 & 4 \\
\hline & 1.07 & 0.05 & 0.62 & 0.04 & 0.58 & 1 & & & & & & \\
\hline & 1.09 & 0.08 & 0.61 & 0.03 & 0.56 & 1 & & & & & & \\
\hline & 1.08 & 0.07 & 0.61 & 0.06 & 0.56 & 1 & & & & & & \\
\hline \multirow[t]{5}{*}{2} & 1.15 & 0.01 & 0.56 & 0.04 & 0.49 & 3 & 1.10 & 0.07 & 0.56 & 0.02 & 5 & 15 \\
\hline & 1.09 & 0.04 & 0.55 & 0.01 & 0.51 & 2 & & & & & & \\
\hline & 1.07 & 0.01 & 0.57 & 0.05 & 0.53 & 3 & & & & & & \\
\hline & 1.07 & 0.06 & 0.55 & 0.03 & 0.51 & 4 & & & & & & \\
\hline & 1.12 & 0.06 & 0.57 & 0.04 & 0.51 & 3 & & & & & & \\
\hline \multirow[t]{3}{*}{3} & 1.14 & 0.08 & 0.59 & 0.05 & 0.52 & 3 & 1.16 & 0.16 & 0.59 & 0.09 & 3 & 9 \\
\hline & 1.10 & 0.00 & 0.55 & 0.06 & 0.50 & 3 & & & & & & \\
\hline & 1.25 & 0.09 & 0.64 & 0.08 & 0.51 & 3 & & & & & & \\
\hline \multirow[t]{3}{*}{4} & 1.28 & 0.13 & 0.66 & 0.08 & 0.52 & 6 & 1.17 & 0.20 & 0.62 & 0.10 & 3 & 12 \\
\hline & 1.17 & 0.07 & 0.62 & 0.09 & 0.53 & 3 & & & & & & \\
\hline & 1.08 & 0.13 & 0.56 & 0.07 & 0.52 & 3 & & & & & & \\
\hline \multirow[t]{4}{*}{5} & 1.19 & 0.19 & 0.66 & 0.10 & 0.55 & 5 & 1.23 & 0.08 & 0.64 & 0.04 & 4 & 15 \\
\hline & 1.20 & 0.32 & 0.62 & 0.07 & 0.52 & 3 & & & & & & \\
\hline & 1.27 & 0.08 & 0.66 & 0.04 & 0.52 & 3 & & & & & & \\
\hline & 1.25 & 0.13 & 0.62 & 0.14 & 0.50 & 4 & & & & & & \\
\hline \multirow[t]{5}{*}{6} & 1.27 & 0.10 & 0.68 & 0.07 & 0.53 & 1 & 1.26 & 0.12 & 0.68 & 0.09 & 5 & 5 \\
\hline & 1.28 & 0.11 & 0.68 & 0.13 & 0.53 & 1 & & & & & & \\
\hline & 1.18 & 0.23 & 0.67 & 0.16 & 0.57 & 1 & & & & & & \\
\hline & 1.22 & 0.22 & 0.62 & 0.07 & 0.51 & 1 & & & & & & \\
\hline & 1.33 & 0.37 & 0.74 & 0.12 & 0.56 & 1 & & & & & & \\
\hline \multirow[t]{6}{*}{7} & 1.29 & 0.08 & 0.70 & 0.04 & 0.54 & 8 & 1.25 & 0.07 & 0.65 & 0.07 & 6 & 31 \\
\hline & 1.28 & 0.08 & 0.62 & 0.11 & 0.48 & 9 & & & & & & \\
\hline & 1.27 & 0.09 & 0.66 & 0.04 & 0.52 & 5 & & & & & & \\
\hline & 1.25 & 0.10 & 0.65 & 0.06 & 0.52 & 3 & & & & & & \\
\hline & 1.22 & 0.19 & 0.66 & 0.23 & 0.54 & 3 & & & & & & \\
\hline & 1.20 & 0.17 & 0.60 & 0.19 & 0.50 & 3 & & & & & & \\
\hline \multirow[t]{4}{*}{8} & 1.27 & 0.11 & 0.64 & 0.06 & 0.51 & 12 & 1.29 & 0.04 & 0.66 & 0.02 & 4 & 25 \\
\hline & 1.29 & 0.10 & 0.66 & 0.05 & 0.51 & 6 & & & & & & \\
\hline & 1.27 & 0.02 & 0.65 & 0.01 & 0.51 & 2 & & & & & & \\
\hline & 1.31 & 0.11 & 0.67 & 0.06 & 0.51 & 5 & & & & & & \\
\hline
\end{tabular}


Table A2 continued: Measurements of $\delta^{30} \mathrm{Si}(\mathrm{OH})_{4}$ and ${ }^{29} \mathrm{Si}(\mathrm{OH})_{4}$ by each laboratory group for ALOHA 1000 .

\begin{tabular}{|c|c|c|c|c|c|c|c|c|c|c|c|c|}
\hline \multirow{2}{*}{$\begin{array}{l}\text { Group } \\
\text { Aloha } \\
1000 \mathrm{~m}\end{array}$} & $\delta^{30} \mathrm{Si}$ & $\begin{array}{c}2 \\
\text { s.d. }\end{array}$ & $\delta^{29} \mathrm{Si}$ & $\begin{array}{c}2 \\
\text { s.d. }\end{array}$ & ${ }^{29 / 30} \mathrm{Si}$ & $\mathbf{n}$ & $\begin{array}{c}\delta^{30} \mathrm{Si} \\
\text { mean }\end{array}$ & $\begin{array}{l}2 \text { s.d. } \\
\text { mean }\end{array}$ & $\begin{array}{c}\delta^{29} \mathrm{Si} \\
\text { mean }\end{array}$ & $\begin{array}{l}2 \text { s.d. } \\
\text { mean }\end{array}$ & $\mathbf{N}$ & $\mathbf{n}$ \\
\hline & [\%o] & [\%o] & [\%o] & [\%o] & [\%o] & $\begin{array}{l}\text { analyt. } \\
\text { replicate }\end{array}$ & [\%o] & [\%o] & [\%o] & [\%o] & & \\
\hline \multirow[t]{10}{*}{9} & 1.32 & 0.08 & 0.69 & 0.01 & 0.52 & 2 & 1.31 & 0.15 & 0.68 & 0.09 & 10 & 20 \\
\hline & 1.35 & 0.07 & 0.74 & 0.13 & 0.55 & 2 & & & & & & \\
\hline & 1.42 & 0.16 & 0.69 & 0.14 & 0.49 & 2 & & & & & & \\
\hline & 1.30 & 0.11 & 0.67 & 0.04 & 0.51 & 2 & & & & & & \\
\hline & 1.35 & 0.21 & 0.70 & 0.06 & 0.52 & 2 & & & & & & \\
\hline & 1.33 & 0.01 & 0.72 & 0.07 & 0.54 & 2 & & & & & & \\
\hline & 1.15 & 0.07 & 0.63 & 0.03 & 0.55 & 2 & & & & & & \\
\hline & 1.24 & 0.07 & 0.64 & 0.24 & 0.51 & 2 & & & & & & \\
\hline & 1.34 & 0.11 & 0.60 & 0.11 & 0.45 & 2 & & & & & & \\
\hline & 1.31 & 0.14 & 0.73 & 0.10 & 0.55 & 2 & & & & & & \\
\hline \multirow[t]{3}{*}{10} & 1.39 & 0.09 & 0.70 & 0.04 & 0.50 & 3 & 1.45 & 0.17 & 0.76 & 0.16 & 3 & 9 \\
\hline & 1.55 & 0.18 & 0.85 & 0.08 & 0.55 & 3 & & & & & & \\
\hline & 1.41 & 0.12 & 0.74 & 0.07 & 0.52 & 3 & & & & & & \\
\hline \multirow[t]{8}{*}{11} & 1.26 & 0.11 & 0.62 & 0.08 & 0.50 & 9 & 1.27 & 0.05 & 0.65 & 0.03 & 8 & 72 \\
\hline & 1.25 & 0.14 & 0.66 & 0.07 & 0.52 & 9 & & & & & & \\
\hline & 1.23 & 0.16 & 0.64 & 0.08 & 0.52 & 9 & & & & & & \\
\hline & 1.27 & 0.10 & 0.65 & 0.12 & 0.51 & 9 & & & & & & \\
\hline & 1.30 & 0.11 & 0.67 & 0.08 & 0.52 & 9 & & & & & & \\
\hline & 1.28 & 0.23 & 0.66 & 0.09 & 0.51 & 9 & & & & & & \\
\hline & 1.30 & 0.16 & 0.66 & 0.09 & 0.50 & 9 & & & & & & \\
\hline & 1.28 & 0.16 & 0.66 & 0.10 & 0.52 & 9 & & & & & & \\
\hline
\end{tabular}


Table A2: Measurements of $\delta^{30} \mathrm{Si}(\mathrm{OH})_{4}$ and ${ }^{29} \mathrm{Si}(\mathrm{OH})_{4}$ by each laboratory group for ALOHA 300 . The means of analytical replicates, $\delta^{30} \mathrm{Si}$ and $\delta^{29} \mathrm{Si}$, and associated 2 sigma standard deviations where analytical replicates are defined as replicate analyses from the same chemical preparation. Averages across chemical preparations within a laboratory group are given by $\delta^{30} \mathrm{Si}$ mean and $\delta^{29} \mathrm{Si}$ mean with associated 2 sigma standard deviations, 2sd_mean. $\mathrm{N}$ and $\mathrm{n}$ denote the total number of chemical preparations and analytical replicates for each laboratory group, respectively. NaN indicates data not available.

\begin{tabular}{|c|c|c|c|c|c|c|c|c|c|c|c|c|}
\hline \multirow{2}{*}{$\begin{array}{l}\text { Group } \\
\text { Aloha } \\
\mathbf{3 0 0} \text { m }\end{array}$} & $\delta^{30} \mathrm{Si}$ & $\begin{array}{c}2 \\
\text { s.d. }\end{array}$ & $\delta^{29} \mathrm{Si}$ & $\begin{array}{c}2 \\
\text { s.d. }\end{array}$ & $\begin{array}{c}29 / 30 \\
\mathrm{Si} \\
\end{array}$ & $\mathbf{n}$ & $\begin{array}{c}\delta^{30} \mathrm{Si} \\
\text { mean }\end{array}$ & $\begin{array}{l}2 \text { s.d. } \\
\text { mean }\end{array}$ & $\begin{array}{c}\delta^{29} \mathrm{Si} \\
\text { mean }\end{array}$ & $\begin{array}{l}2 \text { s.d. } \\
\text { mean }\end{array}$ & $\mathbf{N}$ & $\mathbf{n}$ \\
\hline & [\%o] & [\%o] & [\%o] & [\%o] & [\%o] & $\begin{array}{l}\text { analyt. } \\
\text { replicate }\end{array}$ & [\%o] & [\%o] & [\%o] & [\%o] & & \\
\hline \multirow[t]{6}{*}{2} & 1.75 & 0.02 & 0.83 & 0.03 & 0.48 & 2 & 1.66 & 0.10 & 0.84 & 0.05 & 6 & 12 \\
\hline & 1.64 & 0.01 & 0.87 & 0.05 & 0.53 & 2 & & & & & & \\
\hline & 1.62 & 0.04 & 0.86 & 0.01 & 0.53 & 2 & & & & & & \\
\hline & 1.65 & 0.02 & 0.81 & 0.05 & 0.49 & 2 & & & & & & \\
\hline & 1.67 & 0.03 & 0.81 & 0.02 & 0.49 & 1 & & & & & & \\
\hline & 1.63 & 0.06 & 0.85 & 0.04 & 0.52 & 3 & & & & & & \\
\hline \multirow[t]{4}{*}{4} & 1.56 & 0.06 & 0.87 & 0.09 & 0.55 & 3 & 1.64 & 0.13 & 0.87 & 0.05 & 4 & 12 \\
\hline & 1.60 & 0.12 & 0.83 & 0.02 & 0.52 & 3 & & & & & & \\
\hline & 1.66 & 0.12 & 0.86 & 0.01 & 0.52 & 3 & & & & & & \\
\hline & 1.71 & 0.09 & 0.90 & 0.03 & 0.53 & 3 & & & & & & \\
\hline \multirow[t]{3}{*}{5} & 1.52 & 0.17 & 0.76 & 0.07 & 0.50 & 4 & 1.51 & 0.12 & 0.80 & 0.08 & 3 & 11 \\
\hline & 1.56 & 0.18 & 0.84 & 0.14 & 0.53 & 4 & & & & & & \\
\hline & 1.45 & 0.08 & 0.81 & 0.05 & 0.56 & 3 & & & & & & \\
\hline \multirow[t]{6}{*}{6} & 1.95 & 0.37 & 0.98 & 0.19 & 0.50 & 1 & 1.78 & 0.18 & 0.89 & 0.18 & 6 & 6 \\
\hline & 1.76 & 0.27 & 0.90 & 0.17 & 0.51 & 1 & & & & & & \\
\hline & 1.76 & 0.30 & 0.86 & 0.19 & 0.49 & 1 & & & & & & \\
\hline & 1.75 & 0.07 & 0.74 & 0.16 & 0.42 & 1 & & & & & & \\
\hline & 1.68 & 0.37 & 0.98 & 0.12 & 0.58 & 1 & & & & & & \\
\hline & 1.81 & 0.38 & 0.91 & 0.22 & 0.50 & 1 & & & & & & \\
\hline \multirow[t]{5}{*}{7} & 1.92 & 0.13 & 0.98 & 0.05 & 0.51 & 2 & 1.92 & 0.08 & 1.02 & 0.12 & 5 & 14 \\
\hline & 1.97 & 0.02 & 1.05 & 0.11 & 0.53 & 3 & & & & & & \\
\hline & 1.95 & 0.08 & 1.07 & 0.01 & 0.55 & 3 & & & & & & \\
\hline & 1.87 & 0.30 & 0.94 & 0.32 & 0.50 & 3 & & & & & & \\
\hline & 1.89 & 0.07 & 1.07 & 0.08 & 0.57 & 3 & & & & & & \\
\hline \multirow[t]{3}{*}{8} & 1.51 & 0.05 & 0.77 & 0.05 & 0.51 & 3 & 1.46 & 0.17 & 0.75 & 0.09 & 3 & 10 \\
\hline & 1.52 & 0.04 & 0.77 & 0.02 & 0.51 & 1 & & & & & & \\
\hline & 1.36 & 0.09 & 0.69 & 0.04 & 0.51 & 6 & & & & & & \\
\hline \multirow[t]{8}{*}{9} & 1.90 & 0.01 & 0.95 & 0.06 & 0.50 & 2 & 1.94 & 0.12 & 0.99 & 0.08 & 8 & 16 \\
\hline & 2.05 & 0.16 & 1.06 & 0.08 & 0.52 & 2 & & & & & & \\
\hline & 1.90 & 0.57 & 0.98 & 0.21 & 0.51 & 2 & & & & & & \\
\hline & 1.94 & 0.01 & 0.94 & 0.10 & 0.48 & 2 & & & & & & \\
\hline & 2.02 & 0.42 & 1.04 & 0.11 & 0.51 & 2 & & & & & & \\
\hline & 1.91 & 0.10 & 1.00 & 0.24 & 0.52 & 2 & & & & & & \\
\hline & 1.89 & 0.27 & 0.99 & 0.14 & 0.53 & 2 & & & & & & \\
\hline & 1.95 & 0.27 & 1.01 & 0.10 & 0.52 & 2 & & & & & & \\
\hline
\end{tabular}


Table A2 continued: Measurements of $\delta^{30} \mathrm{Si}(\mathrm{OH})_{4}$ and ${ }^{29} \mathrm{Si}(\mathrm{OH})_{4}$ by each laboratory group for ALOHA 300 .

\begin{tabular}{|c|c|c|c|c|c|c|c|c|c|c|c|c|}
\hline $\begin{array}{l}\text { Group } \\
\text { Aloha } \\
\mathbf{3 0 0} \mathbf{~ m}\end{array}$ & $\delta^{30} \mathrm{Si}$ & $\begin{array}{c}2 \\
\text { s.d. }\end{array}$ & $\delta^{29} \mathrm{Si}$ & $\begin{array}{c}2 \\
\text { s.d. }\end{array}$ & $\begin{array}{c}29 / 30 \\
\mathrm{Si}\end{array}$ & $\mathbf{n}$ & $\begin{array}{c}\delta^{30} \mathrm{Si} \\
\text { mean }\end{array}$ & $\begin{array}{l}2 \text { s.d. } \\
\text { mean }\end{array}$ & $\begin{array}{c}\delta^{29} \mathrm{Si} \\
\text { mean }\end{array}$ & $\begin{array}{l}2 \text { s.d. } \\
\text { mean }\end{array}$ & $\mathbf{N}$ & $\mathbf{n}$ \\
\hline & [\%o] & [\%o] & [\%o] & [\%o] & [\%o] & $\begin{array}{l}\text { analyt. } \\
\text { replicate }\end{array}$ & [\%o] & [\%o] & [\%o] & [\%o] & & \\
\hline 10 & 1.52 & 0.04 & 0.77 & 0.02 & 0.51 & 3 & 1.53 & 0.17 & 0.79 & 0.06 & 3 & 9 \\
\hline & 1.45 & 0.05 & 0.77 & 0.02 & 0.53 & 3 & & & & & & \\
\hline & 1.61 & 0.07 & 0.82 & 0.06 & 0.51 & 3 & & & & & & \\
\hline 11 & 1.61 & naN & 0.88 & naN & 0.55 & 1 & 1.69 & 0.24 & 0.85 & 0.17 & 8 & 8 \\
\hline & 1.82 & naN & 0.97 & naN & 0.54 & 1 & & & & & & \\
\hline & 1.73 & naN & 0.90 & naN & 0.52 & 1 & & & & & & \\
\hline & 1.52 & naN & 0.71 & naN & 0.46 & 1 & & & & & & \\
\hline & 1.60 & naN & 0.77 & naN & 0.48 & 1 & & & & & & \\
\hline & 1.76 & naN & 0.91 & naN & 0.52 & 1 & & & & & & \\
\hline & 1.86 & naN & 0.85 & naN & 0.46 & 1 & & & & & & \\
\hline & 1.61 & naN & 0.80 & naN & 0.50 & 1 & & & & & & \\
\hline
\end{tabular}


Table A3: Summary of mean Si isotope values $\left(\delta^{30} \mathrm{Si}, \delta^{29} \mathrm{Si}\right)$, the associated $2 \sigma$ analytical uncertainty $(2 \mathrm{~s}$. d.) and the number of measurements (n) obtained by each laboratory group for the secondary standards Big Batch and Diatomite. The overall mean and the uncertainty about the mean $(2 \mathrm{~s}$. d. $)$ as well as the median and the interquartile deviation (IQD) for all groups are given at the bottom of the table. NaN indicates data not available.

\begin{tabular}{|c|c|c|c|c|c|c|c|c|c|c|}
\hline \multirow[b]{2}{*}{ Group } & \multicolumn{5}{|c|}{ Big Batch } & \multicolumn{5}{|c|}{ Diatomite } \\
\hline & $\delta^{30} \mathrm{Si}$ & 2 s.d. & $\delta^{29} \mathrm{Si}$ & 2 s.d. & n & $\delta^{30} \mathrm{Si}$ & 2 s.d. & $\delta^{29} \mathrm{Si}$ & 2 s.d. & $\mathbf{n}$ \\
\hline 1 & -10.61 & 0.08 & -5.42 & 0.07 & 18 & 1.25 & 0.11 & 0.64 & 0.09 & 15 \\
\hline 2 & $\mathrm{NaN}$ & $\mathrm{NaN}$ & $\mathrm{NaN}$ & $\mathrm{NaN}$ & $\mathrm{NaN}$ & 1.26 & 0.14 & 0.66 & 0.12 & 14 \\
\hline 3 & -10.48 & 0.34 & $\mathrm{NaN}$ & $\mathrm{NaN}$ & 3 & $\mathrm{NaN}$ & $\mathrm{NaN}$ & $\mathrm{NaN}$ & $\mathrm{NaN}$ & $\mathrm{NaN}$ \\
\hline 4 & $\mathrm{NaN}$ & $\mathrm{NaN}$ & $\mathrm{NaN}$ & $\mathrm{NaN}$ & $\mathrm{NaN}$ & 1.25 & 0.13 & $\mathrm{NaN}$ & $\mathrm{NaN}$ & 19 \\
\hline 5 & -10.67 & 0.16 & -5.43 & 0.10 & 5 & 1.23 & 0.05 & 0.63 & 0.04 & 4 \\
\hline 6 & -10.64 & 0.22 & -5.43 & 0.10 & 34 & $\mathrm{NaN}$ & $\mathrm{NaN}$ & $\mathrm{NaN}$ & $\mathrm{NaN}$ & $\mathrm{NaN}$ \\
\hline 7 & -10.50 & 0.08 & -5.36 & 0.06 & 3 & $\mathrm{NaN}$ & $\mathrm{NaN}$ & $\mathrm{NaN}$ & $\mathrm{NaN}$ & $\mathrm{NaN}$ \\
\hline 8 & -10.51 & 0.23 & -5.35 & 0.11 & 25 & 1.27 & 0.16 & 0.66 & 0.07 & 5 \\
\hline 9 & -10.48 & 0.08 & $\mathrm{NaN}$ & $\mathrm{NaN}$ & 2 & $\mathrm{NaN}$ & $\mathrm{NaN}$ & $\mathrm{NaN}$ & $\mathrm{NaN}$ & $\mathrm{NaN}$ \\
\hline 10 & $\mathrm{NaN}$ & $\mathrm{NaN}$ & $\mathrm{NaN}$ & $\mathrm{NaN}$ & $\mathrm{NaN}$ & $\mathrm{NaN}$ & $\mathrm{NaN}$ & $\mathrm{NaN}$ & $\mathrm{NaN}$ & $\mathrm{NaN}$ \\
\hline 11 & $\mathrm{NaN}$ & $\mathrm{NaN}$ & $\mathrm{NaN}$ & $\mathrm{NaN}$ & $\mathrm{NaN}$ & $\mathrm{NaN}$ & $\mathrm{NaN}$ & $\mathrm{NaN}$ & $\mathrm{NaN}$ & $\mathrm{NaN}$ \\
\hline Mean & -10.56 & & -5.40 & & & 1.25 & & 0.65 & & \\
\hline 2 s.d. & 0.16 & & 0.08 & & & 0.03 & & 0.03 & & \\
\hline Median & -10.51 & & -5.42 & & & 1.25 & & 0.65 & & \\
\hline IQD & 0.07 & & 0.04 & & & 0.01 & & 0.01 & & \\
\hline
\end{tabular}


Table A4: Statistical Analysis of Differences in differences in $\delta^{30} \mathrm{Si}(\mathrm{OH})_{4}$ among groups using Neptune spectrometers. Groups not connected by same letter are significantly different.

\begin{tabular}{|c|c|c|c|c|c|}
\hline \multicolumn{6}{|c|}{$\mathrm{ALOHA}_{1000}$} \\
\hline & \multicolumn{2}{|c|}{ Tukey } & \multicolumn{2}{|c|}{ False Discovery Rate } & Mean \\
\hline Group & Column A & Column B & Column A & Column B & \\
\hline 11 & $\mathrm{~A}$ & & $\mathrm{~A}$ & & 1.27 \\
\hline 2 & & $\mathrm{~B}$ & $\mathrm{~A}$ & B & 1.16 \\
\hline 3 & & B & & B & 1.10 \\
\hline 1 & & $\mathrm{~B}$ & & B & 1.10 \\
\hline \multicolumn{6}{|c|}{$\mathrm{ALOHA}_{300}$} \\
\hline & \multicolumn{2}{|c|}{ Tukey } & & & \\
\hline Group & Column A & Column B & & & \\
\hline 11 & $\mathrm{~A}$ & & & & 1.69 \\
\hline 2 & A & & & & 1.66 \\
\hline
\end{tabular}


1

2

5

6

7

8

9

10

11

12

13

14

15

16

17

18

19

20

21

22

23

24

25

26

27

28

29

30

31

32

33

34

35

36

37

38

39

40

41

42

43

44

45

46

47

48

49

50

51

52

53

54

55

56

57

58

59

60

Table A5: Statistical Analysis of Differences in differences in $\delta^{30} \mathrm{Si}(\mathrm{OH})_{4}$ among groups using Nu Plasma mass spectrometers. Groups not connected by same letter are significantly different.

\begin{tabular}{|c|c|c|c|c|}
\hline \multicolumn{5}{|c|}{$\mathrm{ALOHA}_{1000}$} \\
\hline & \multicolumn{3}{|c|}{ Tukey } & Mean $\delta^{30} \mathrm{Si}(\mathrm{OH})_{4}$ \\
\hline Group & Column A & Column B & Column C & \\
\hline 10 & $\mathrm{~A}$ & & & 1.45 \\
\hline 9 & & $\mathrm{~B}$ & & 1.31 \\
\hline 6 & & B & $\mathrm{C}$ & 1.26 \\
\hline 7 & & $\mathrm{~B}$ & $\mathrm{C}$ & 1.25 \\
\hline 5 & & $\mathrm{~B}$ & $\mathrm{C}$ & 1.23 \\
\hline 4 & & & $\mathrm{C}$ & 1.18 \\
\hline & & & & \\
\hline \multicolumn{5}{|c|}{$\mathrm{ALOHA}_{300}$} \\
\hline 9 & $\mathrm{~A}$ & & & 1.94 \\
\hline 7 & $\mathrm{~A}$ & & & 1.92 \\
\hline 6 & & $\mathrm{~B}$ & & 1.78 \\
\hline 4 & & & $\mathrm{C}$ & 1.64 \\
\hline 10 & & & $\mathrm{C}$ & 1.53 \\
\hline 5 & & & $\mathrm{C}$ & 1.51 \\
\hline
\end{tabular}


Figure $1 . \delta^{30} \mathrm{Si}(\mathrm{OH})_{4}$ results from all groups for $\mathrm{ALOHA}_{300}$ (open circles) and ALOHA 1000 (filled circles). The long black vertical solid line indicates the mean value of all measurements for $A L O H A_{1000}$ and the long dashed line that for $\mathrm{ALOHA}_{300}$. The data points represent the individual $\delta^{30} \mathrm{Si}(\mathrm{OH})_{4}$ values from Table

A2. Short vertical solid lines are the means obtained by individual laboratories for the two samples. Uncertainty in the mean for all measurements for each sample ( $2 \mathrm{~s}$. d.) is indicated by the horizontal bars at the top of the figure.

Fig. 1

$188 \times 141 \mathrm{~mm}(300 \times 300 \mathrm{DPI})$ 


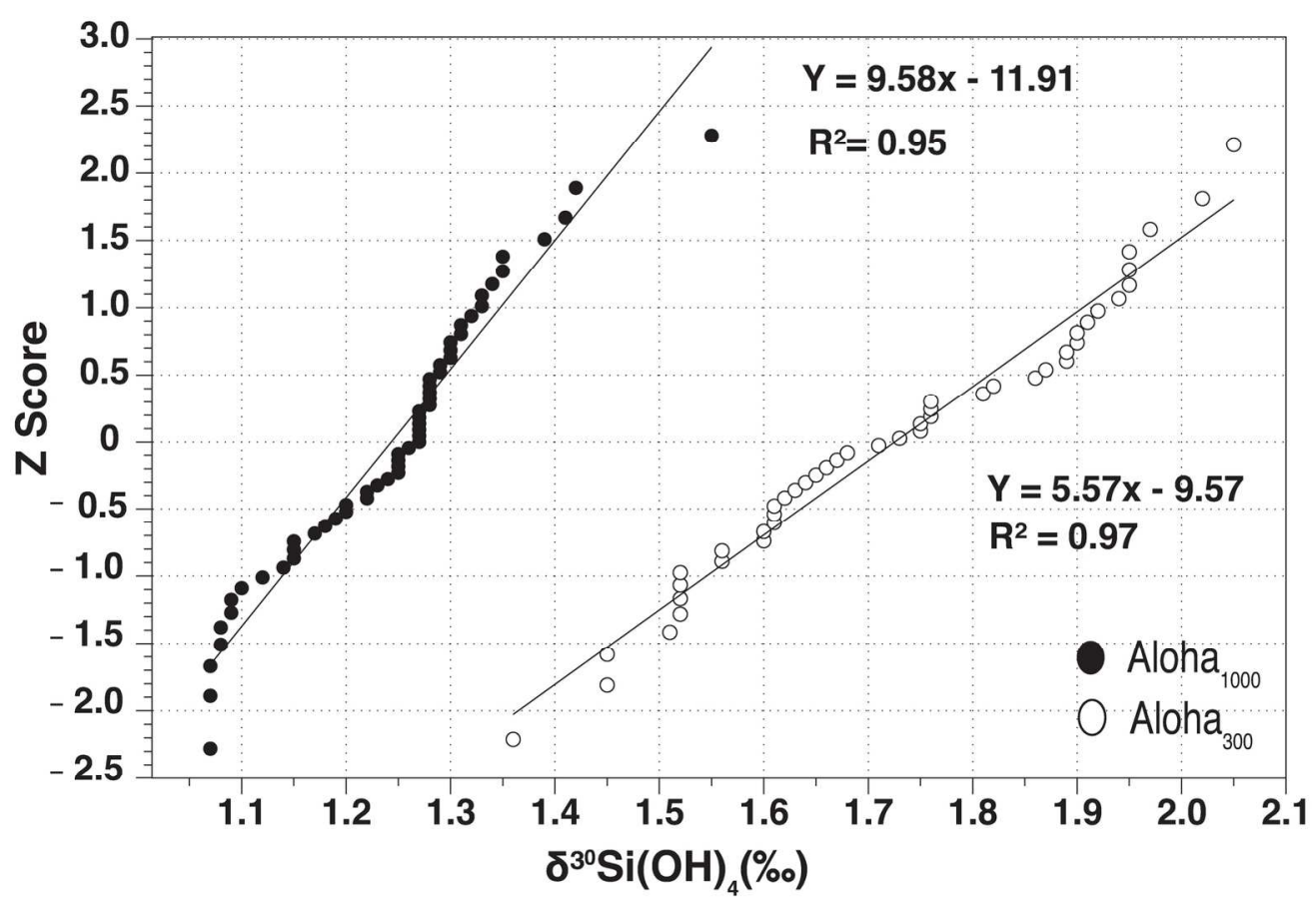

Figure 2. $\mathrm{Z}$ scores as a function of $\delta^{30} \mathrm{Si}(\mathrm{OH})_{4}$ for $\mathrm{ALOHA}_{300}$ (open circles) and $\mathrm{ALOHA}_{1000}$ (filled circles). Fig. 2 


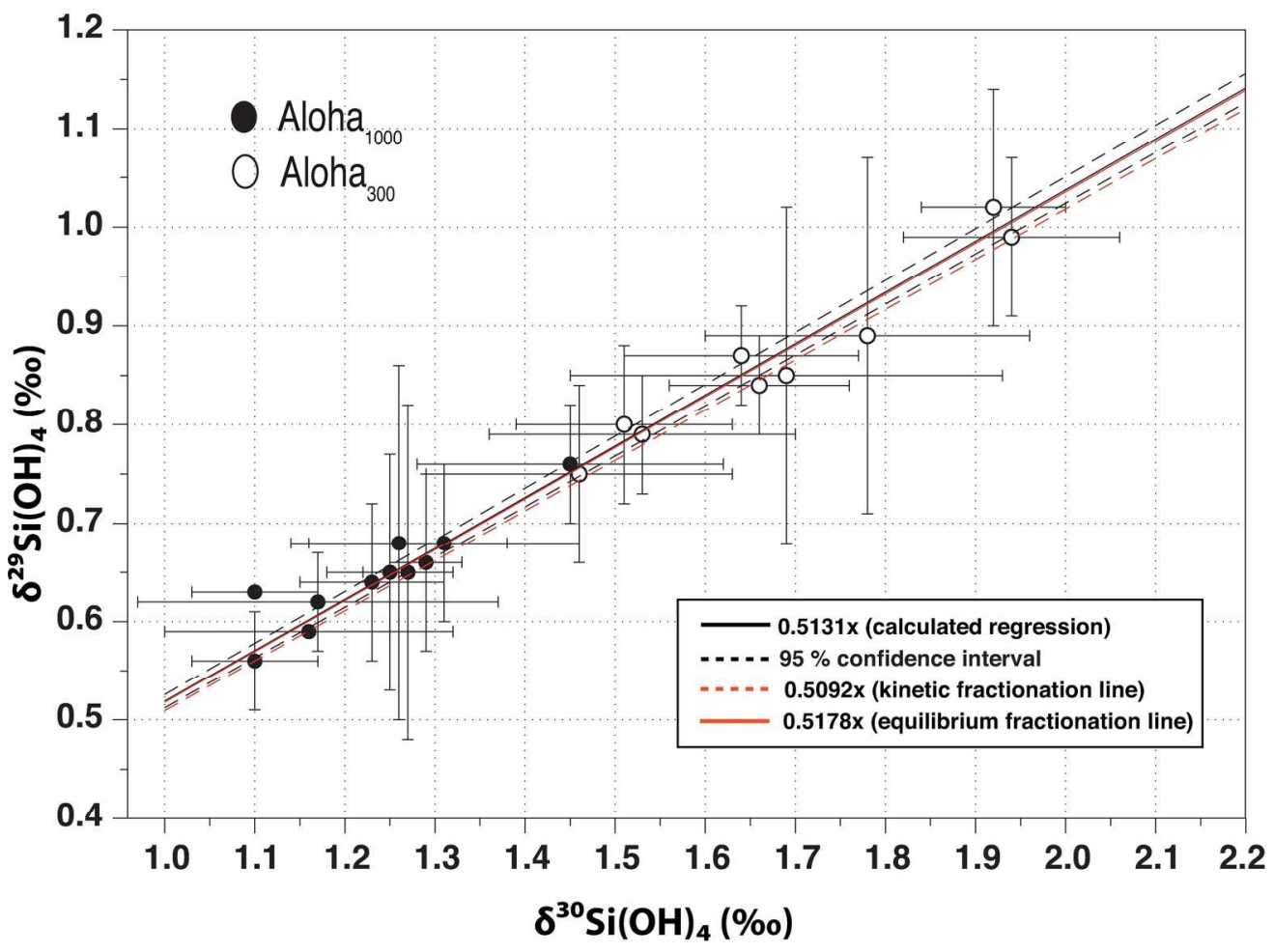

Figure 3. Plot of $\delta^{30} \mathrm{Si}(\mathrm{OH})_{4}$ versus $\delta^{29} \mathrm{Si}(\mathrm{OH})_{4}$ for ALOHA300 (open circle) and ALOHA 1000 (filled circle; error bars are $2 \mathrm{~s}$. d.). Solid line is the result of least-squares linear regression with a slope of $0.5188 \pm 0.0184$ (s.e., $\left.\mathrm{R}^{2}=0.98\right)$. The lower and upper $95 \%$ confidence intervals are given as dashed black lines. The kinetic fractionation line has a slope of 0.5092 (intercept of zero) for Si (dashed red line) and the equilibrium fractionation line has a slope of 0.5178 (intercept of zero) for Si (solid red line). Regression line obtained by analysis using reduced major axis model II regression yields a slope of $0.5131 \pm 0.0040$ (s.e., $R^{2}=0.98$; not displayed in the figure).

Fig. 3

$176 \times 131 \mathrm{~mm}(300 \times 300 \mathrm{DPI})$ 

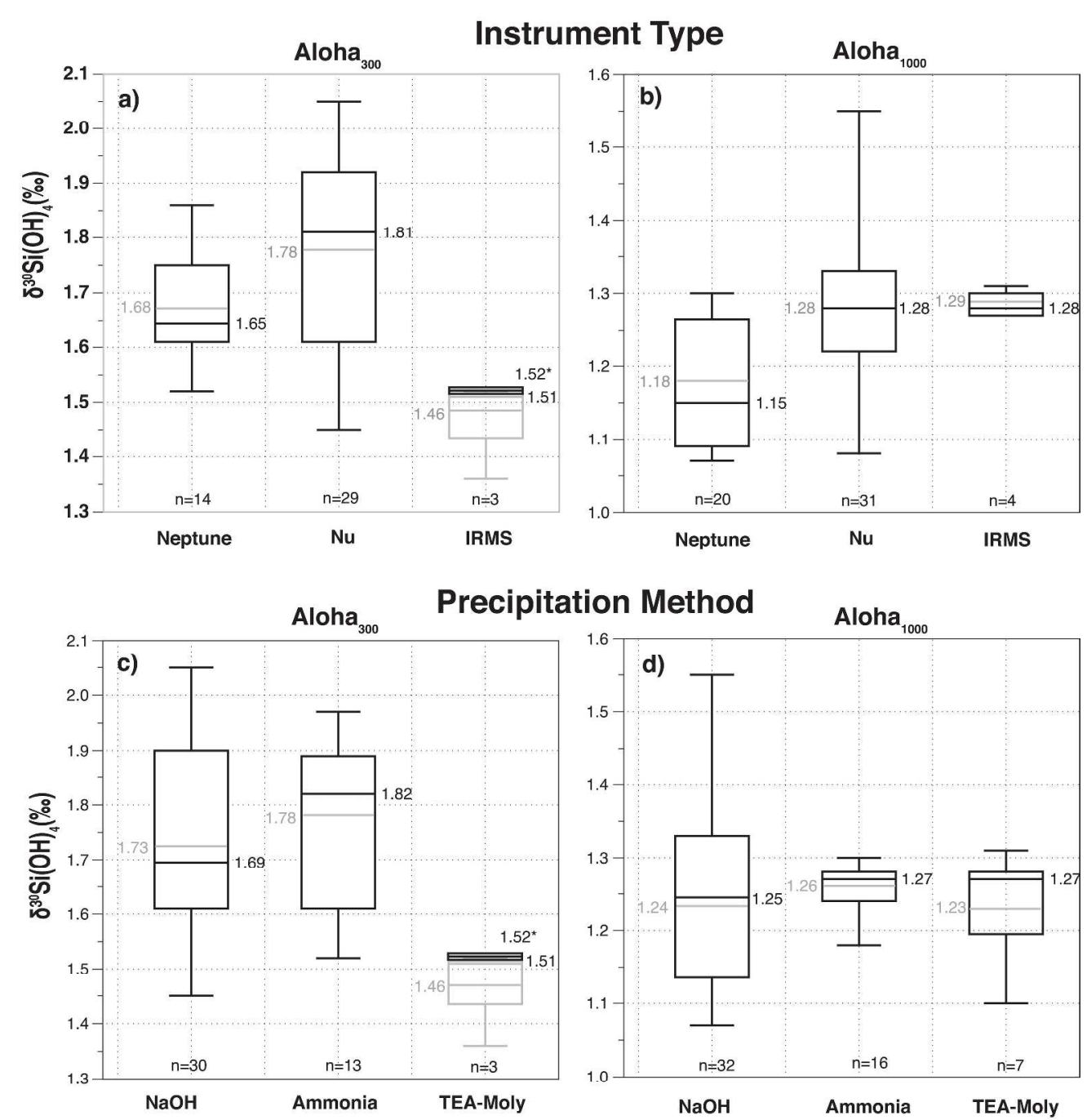

\section{ation Method}

Aloha $_{1000}$

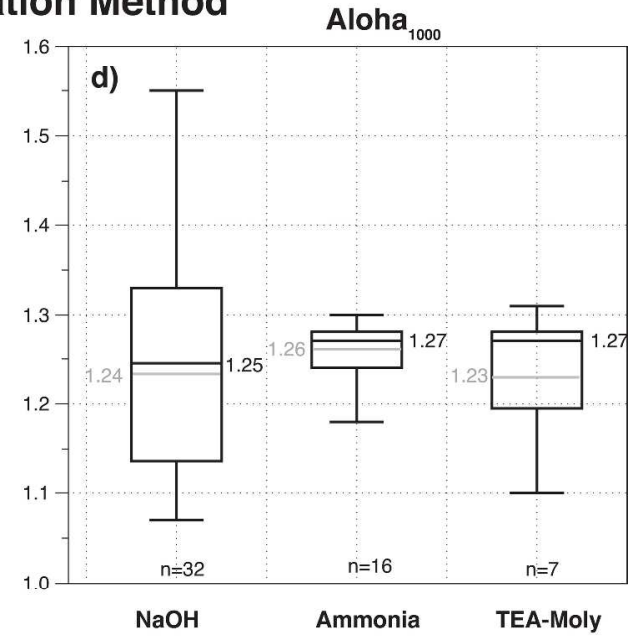

Figure 4. Boxplots showing $\delta^{30} \mathrm{Si}(\mathrm{OH})_{4}$ data sorted by different mass spectrometer types for a) $\mathrm{ALOHA}_{300}$ and for b) ALOHA $A_{1000}$. Data sorted by different precipitation methods for c) ALOHA 300 and d) ALOHA $A_{1000}$. On the boxplots the median values (black) and the mean values (grey) are displayed. For $\mathrm{ALOHA}_{300}$ a) and c) show data for IRMS and TEA-Moly with (grey boxplot) and without outlier (black boxplot). Here, the mean value (which equals the median) is indicated by a superscript star. The value next to each boxplot indicates the median (black) and the mean (grey), respectively. The number of included data points ( $\mathrm{n}$ ) is given below each boxplot. Raw data are presented in Table 3

Fig. 4 $334 \times 402 \mathrm{~mm}(300 \times 300$ DPI $)$ 